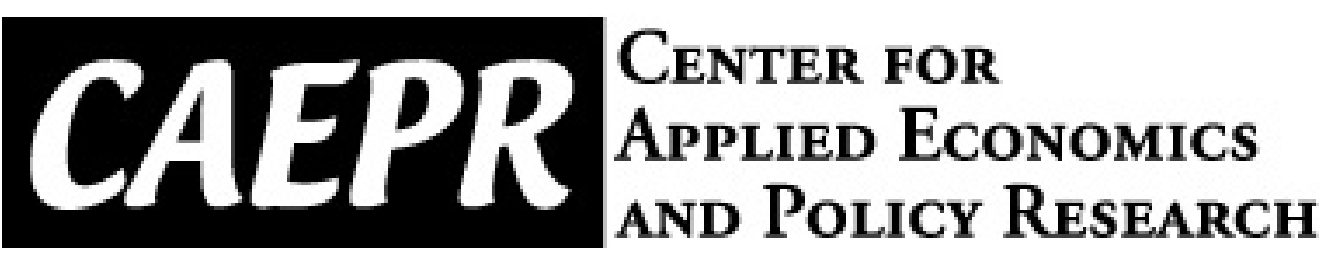

CAEPR Working Paper

\#2008-023

\title{
Should Dynamic Scoring be done with Heterogeneous Agent-Based Models? Challenging the Conventional Wisdom
}

\author{
M Saifur Rahman \\ Indiana University Bloomington
}

September 19, 2008

This paper can be downloaded without charge from the Social Science Research Network electronic library at: http://ssrn.com/abstract=1270634.

The Center for Applied Economics and Policy Research resides in the Department of Economics at Indiana University Bloomington. CAEPR can be found on the Internet at:

http://www.indiana.edu/ caepr. CAEPR can be reached via email at caepr@indiana.edu or via phone at 812-855-4050.

(02008 by M Saifur Rahman. All rights reserved. Short sections of text, not to exceed two paragraphs, may be quoted without explicit permission provided that full credit, including $\odot$ notice, is given to the source. 


\title{
Should Dynamic Scoring be done with Heterogeneous Agent-Based Models? Challenging the Conventional wisdom
}

\author{
M Saifur Rahman* \\ Department of Economics \\ Indiana University at Bloomington \\ Email: murahman@indiana.edu \\ Phone: 812-855-0179
}

September 17, 2008

\begin{abstract}
Traditionally, Dynamic Scoring calculations experiements are carried out using representative agent based macroeconomic models. Existing literature does not provide any objection to this approach. In this paper, I develop a heterogeneous agent model similar to the SaverSpenders model of Mankiw(2000). But spenders in my model are merely credit constrained and not Rule of thumb consumers. Both groups are intertemporal optimizers because of the existence of Internal Habit Persistence. Transition path of most of the macro and fiscal variables for various tax cuts under alternative financing scheme shows pattern which are significantly different and sometimes contrasting to the representative agent model. Dynamic scoring calculations reveal a downward bias of the representative agent model. Underestimation of the dynamic response could be as large as $45 \%$. Finally, steady state results indicate smaller impact of contractionary policies on major fiscal variables such as net tax revenue and tax base. Over all, the paper argues that the need to use heterogeneous agent based model in dynamic fiscal calculations is not only desirable but also essential.

Key Words: Savers-spenders model, rule-of thumb consumer, intertemporal optimizers, dynamic scoring, habit persistence, alternative financing, debt financing, fiscal policy
\end{abstract}

JEL code: E62, H2, H3, H6

\section{Introduction}

Should we use heterogeneous agent based model to analyze aggregate change rather than representative agent based model? More precisely, should we use models that have rich heterogeneity across their agents in terms of market participation, preference and labor supply decisions to analyze policy experiments such as dynamic scoring that focus on the aggregate implications of alternative fiscal policies? The conventional wisdom among policy making agencies and to some extent, in the literature is the following; although heterogeneous agent based models are crucial for analyzing distributional policies, for standard dynamic fiscal policy analysis where the main focus is the aggregate effect such as debt financing and dynamic scoring, the representative agent based model, although subject to minor measurement error, could provide a reasonable approximation to macroeconomic response to various policy changes, and therefore could be used as

*I would like to thank my Advisor, Eric Leeper, for his valuable suggesstions during my research. I would like to specially thank Nora Traum for her valuable comments and also for sharing matlab codes for Leeper and Yang(2006). I would also like to thank Susan Yang for providing code for the steady state calculations of Leeper and Yang(2006) and helping me to understand the fundamentals of dynamic scoring. Finally, I thank all the participants of the Fall 2007 Macroeconomics Brown Bag workshop. All errors are mine 
a benchmark without any discretion. This paper attempts to refute this conventional wisdom and tries to answer these questions by adopting a heterogenous agent based general equilibrium model to carry out one fiscal policy experiments. The experiment is known as the Dynamic scoring exercise undertaken by Joint Committee of Taxation(with the support from the Congressional Budget Office) . I systematically employ different layers of heterogeneity to the model to highlight the importance of various kinds of heterogeneity. The paper consistently show that heterogeneity can be very important not only for the distributional consequences but also for the aggregate implications. While most of the existing literature either puts less importance on the degree of heterogeneity or most of the times completely ignores it by using representative agent base models, this paper argues that using representative agent based model for dynamic scoring in general could be seriously misleading. This could lead to conclusions which are qualitatively and quantitatively different from a heterogeneous agent-based model's predictions.

\section{Dynamic Fiscal Policy and Economic Modelling}

Dynamic scoring is the analysis of changes in tax revenue as a result of a proposed tax change by incorporating dynamic macroeconomic effects. It is therefore, an analysis of dynamic fiscal policy. There is a large group of papers that analyze the effect of fiscal policy in a the framework of a representative agent based model. These papers focus on the aggregate implications of the economy and bypass the analysis of the distributional effect of the fiscal policy. This large group includes, but not limited to, fundamental contributions from Baxter and King(1993), King and Rebelo(2002), King and Rebelo(1990), McGrattan(1994) Leeper and Yang(2006) and important contributions from Trabandt and Uhlig(2005), Gordon and Leeper(2005), Novales and Ruiz(2002). But recently, there has been exciting new development of a class of models that retain the tractable nature of the representative agent model while introduce some degree of heterogeneity across agents which enable them to provide limited but important insight into the distributional/ disaggregate effect of fiscal policy. Papers from this new and rapidly increasing pool includes Mankiw(2000), Mankiw and Weinzierl(2006), Gali, Salido and Valles(2004.a,JMCB and 2004.b), Erceg, Guerrieri and Gust(2005), Forni,Monforte and Sessa(2006), Colciago(2007) and Yang(2007). All these papers use a new kind of heterogenous agent based model first pioneered by Campbell and Makiw(1989). In this model, there are two kinds of agents. The first groups are called the savers who have access to the credit market/or actually save by participating in the credit market. The second groups are called the spenders who do not have any access to the credit market/or does not save. Therefore, this model has a unique combination of agents who follow life cycle hypothesis(savers) and agents who do not. This model draws support from several important empirical papers. First, Porteba(1988) found that anticipated tax change did not change consumption of some people. This, his argued, was an evidence of the Violation of LCH/PIH. Wolff(1998, 2001) looked at the Survey of credit finance data and found that almost $40 \%$ of the people surveyed had zero/negative wealth. Finally, Shapiro and Slemrod(1995) asked what people will do with the extra money from Bush's 1992 tax cut. 43\% said they would spend the entire money. All these findings suggest that a hybrid model such as the Campbell and Mankiw(1989) would be a better approximation of the reality and could be used for more accurate policy analysis. Many empirical papers(Forni, Monforte, and Sessa (2006), Erceg, Guerrieri and Gust(2005)) have used this model to carry econometric works and found success.

Outside the academic work, policy institutions such as the Joint Committee of Taxation and the Congressional Budget Office carry out analysis of dynamic fiscal policy. Surprisingly, in almost all instances, their modeling choice involves using representative agent based models or 
simple overlapping generations models that only capture Intergenerational heterogeneity ${ }^{1}$. Papers that are aligned with policy institutions also use representative agent based models(for example, Mankiw and Weinzierl(2006), Bruce and Turnovsky (1999)).

The use of simple representative agent based modeling for important fiscal policy analysis has raised concern among academics and policy makers. It is strongly argued that the aggregate predictions from disaggregate heterogenous based models are different from predictions made by aggregate representative agent based models, as was summarized by Heathcote(2005) . This however, is not without criticism. Auerbach(2000) and Mankiw(2000) argue that it is imperative to use heterogenous agent based models for dynamic fiscal policy analysis such as dynamic scoring because they can provide additional distributional results for the policy makers. But the former is very skeptical about the possibility of different aggregate implications from these models. Finally, Mankiw and Weinzierl(2006) reports that using a heterogenous models such as the saver-spender model does not change the prediction of the representative agent models. Despite that, Joint Committee of Taxation(2006) have introduced the saver-spender model in its dynamic scoring analysis.

The present paper will develop a modified version of the savers-spenders model. We argue that the use of standard saver-spender model in the dynamic fiscal policy analysis has been fruitless so far because of some inherent limitations of the model which are rather unrealistic. All the previous papers that have used three crucial assumptions in their saver-spender model, which to our view, dampens the relative importance of the heterogeneity in their models. First, the spenders do not have access to the credit market. Second, these models assume that the spenders are Rule of Thumb Consumers in the sense that they do not participate in the labor market and take the wage bargained by the saver as given. third, the spenders are not intertemporal optimizers. The only paper that challenges these assumptions is Yang(2007) who assumes the first two assumptions but models spenders as intra-temporal optimizers. Yet she still gets results very similar to the Mankiw and Weinzierl(2006). In my paper, I argue that the spenders could be credit constrained and at the same time intertemporal optimizers. I impose the assumption of Internal Habit Persistence on the preference of both the saver and the spender. This forces everyone in the economy to think at the intertemporal margins. We will show that the impulse response of all the major macro and fiscal variables for various tax shocks look quite different and sometimes contrasting to the representative agent based model.

\section{The Model}

Following Mankiw(2000), Yang(2007) and JCT(2006), the economy has two types of infinitelylived agents: savers and non-savers, competitive firms, and a government. Both the population and the total amount of time an agent is endowed with are normalized to 1 . A fraction $F$ of the agents are savers and the remaining $(1-F)$ are spenders.

\subsection{Optimization of the Saver}

The savers consume, save and work in this model. The representative saver chooses Consumption $\left(C_{t}^{a}\right)$, Investment $\left(I_{t}^{a}\right)$, Capital $\left(K_{t}^{a}\right)$, Government issued one period bonds $\left(B_{t}^{a}\right)$, and $\operatorname{Labour}\left(L_{t}^{a}\right)$ to maximize utility over consumption and leisure $\left(1-L_{t}^{a}\right)$ :

\footnotetext{
${ }^{1}$ To this date, Joint Committe of Taxation uses four models for their fiscal policy analysis; Joint Committee macroeconomic equilibrium growth model(MEG), the overlapping generations lifecycle model (OLG), Global Insight econometric model(GI) and a dynamic stochastic general equilibrium neoclassical growth model with infinitely lived agents (DSGE). The Congressional Budget Office uses different versions of the OLG model, the Ramsey model, the GI model and a "Macroadvisers' Model" which is also a representative agent based model. For a detailed description of each of these models, see Joint Committee of Taxation(2005a, b) and Dennis and Page(2003).
} 


$$
\underset{\left\{C_{t}^{a}, K_{t}^{a}, L_{t}^{a}\right\}}{\operatorname{Max}} E_{t} \sum_{t=0}^{\infty} \beta_{1}^{t}\left[\frac{\left(C_{t}^{* a}\right)^{1-\gamma_{1}}-1}{1-\gamma_{1}}+\chi^{a} \frac{\left(1-L_{t}^{a}\right)^{1-\theta_{1}}}{1-\theta_{1}}\right]
$$

subject to the budget constraint:

$$
\begin{gathered}
C_{t}^{a}+I_{t}^{a}+B_{t}^{a} \leq\left(1-\tau_{t}^{k}\right) r_{t} K_{t-1}^{a}+\left(1-\tau_{t}^{L_{a}}\right) W_{t} L_{t}^{a}+R_{t-1}^{b} B_{t-1}^{a}+t r_{t}^{a} \\
C_{t}^{* a}=C_{t}^{a}-b_{1} C_{t-1}^{a}
\end{gathered}
$$

The law of motion for capital has the following form:

$$
K_{t}^{a}=(1-\delta) K_{t-1}^{a}+I_{t}^{a}
$$

The superscript $a$ and $p$ indicate variables associated with the saver and the non-saver. $\beta_{1}$ is the subjective discount factor for the saver. The elasticity of intertemporal substitution(IES) for the consumption and leisure for the saver are $\frac{1}{\gamma_{1}}$ and $\frac{1}{\theta_{1}} \operatorname{respectively}\left(\gamma_{1}>0, \theta_{1} \geq 0\right)$. The Frisch elasticity of leisure is defined as $\frac{\left(1-L_{t}^{a}\right)}{\theta_{1} L_{t}^{a}} \cdot r_{t}$ and $W_{t}$ are respectively the rental rate of capital and the wage rate. $\tau_{t}^{k}, \tau_{t}^{L_{a}}$ are tax rate on capital and labour income of the saver. $\delta$ is the economic depreciation rate of capita . $\chi^{a}$ is the weight that saver places on leisure. $b_{1}$ indicates the degree of internal habit persistence for the saver.

The Lagrangian function for the optimization problem after combining (2) and (4) is written as follows:

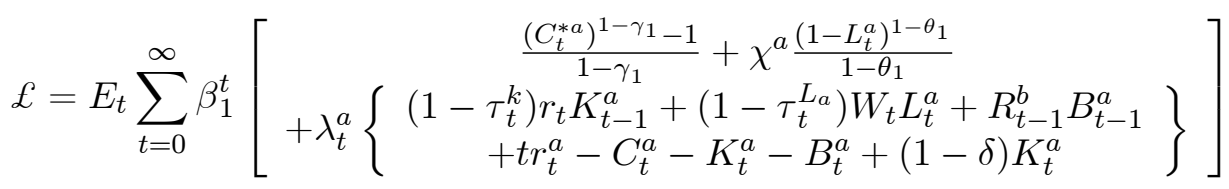

The first order conditions are as follows:

$$
\begin{gathered}
\left(C_{t}^{* a}\right)^{-\gamma_{1}}-E_{t} \beta_{1} b_{1}\left(C_{t+1}^{* a}\right)^{-\gamma_{1}}=\lambda_{t}^{a} \\
\chi^{a}\left(1-L_{t}^{a}\right)^{-\theta_{1}}=\lambda_{t}^{a}\left(1-\tau_{t}^{L_{a}}\right) W_{t} \\
\lambda_{t}^{a}=E_{t} \beta_{1} \lambda_{t+1}^{a}\left\{\left(1-\tau_{t+1}^{k}\right) r_{t+1}+(1-\delta)\right\} \\
\lambda_{t}^{a}=E_{t} \beta_{1} \lambda_{t+1}^{a} R_{t}^{b}
\end{gathered}
$$

Define,

$$
R_{t}^{k}=\left(1-\tau_{t}^{k}\right) r_{t}+(1-\delta)
$$

Therefore, equation (8) could be re-written as:

$$
\lambda_{t}^{a}=E_{t} \beta_{1} \lambda_{t+1}^{a} R_{t+1}^{k}
$$

Combining (6) and (7) and substituting (3), we get:

$$
\chi^{a}\left(1-L_{t}^{a}\right)^{-\theta_{1}}=\left\{\left(C_{t}^{a}-b_{1} C_{t-1}^{a}\right)^{-\gamma_{1}}-E_{t} \beta_{1} b_{1}\left(C_{t+1}^{a}-b_{1} C_{t}^{a}\right)^{-\gamma_{1}}\right\}\left(1-\tau_{t}^{L_{a}}\right) W_{t}
$$

Equation(11.a) shows that the labor supply decisions of the saver depends on the intertemporal consumption decisions. 


\subsection{Optimization of the Spender}

The spenders consume and work in this model. The representative spender chooses Consumption $\left(C_{t}^{p}\right)$ and $\operatorname{Labour}\left(L_{t}^{p}\right)$ to maximize utility over consumption and leisure $\left(1-L_{t}^{p}\right)$ :

$$
\underset{\left\{C_{t}^{p}, L_{t}^{p}\right\}}{\operatorname{Max}}: E_{t} \sum_{t=0}^{\infty} \beta_{2}^{t}\left[\frac{\left(C_{t}^{* p}\right)^{1-\gamma_{2}}-1}{1-\gamma_{2}}+\chi^{p} \frac{\left(1-L_{t}^{p}\right)^{1-\theta_{2}}}{1-\theta_{2}}\right]
$$

subject to the budget constraint:

$$
\begin{gathered}
C_{t}^{p} \leq\left(1-\tau_{t}^{L_{p}}\right) W_{t} L_{t}^{p}+t r_{t}^{p} \\
C_{t}^{* p}=C_{t}^{p}-b_{2} C_{t-1}^{p}
\end{gathered}
$$

Here $\gamma_{2}, b_{2}, \tau_{t}^{L p}, \chi^{p}$ has the usual interpretation for the spender.

The first order conditions are as follows:

$$
\begin{gathered}
\left(C_{t}^{* p}\right)^{-\gamma_{2}}-E_{t} \beta_{2} b_{2}\left(C_{t+1}^{* p}\right)^{-\gamma_{2}}=\lambda_{t}^{p} \\
\chi^{p}\left(1-L_{t}^{p}\right)^{-\theta_{2}}=\lambda_{t}^{p}\left(1-\tau_{t}^{L_{p}}\right) W_{t}
\end{gathered}
$$

Combining (15) and (16) and substituting (14), we get:

$$
\chi^{p}\left(1-L_{t}^{p}\right)^{-\theta_{2}}=\left\{\left(C_{t}^{p}-b_{2} C_{t-1}^{p}\right)^{-\gamma_{2}}-E_{t} \beta_{2} b_{2}\left(C_{t+1}^{p}-b_{2} C_{t}^{p}\right)^{-\gamma_{2}}\right\}\left(1-\tau_{t}^{L_{p}}\right) W_{t}
$$

There are several interesting feature of the spender's preference structure. First habit persistence makes consumption non-separable in time for agents. Therefore, intertemporal consumption decisions force agents to make intertemporal labor decisions, even for spenders. This becomes clear if we look at (16.a). Suppose there is an expected increase in $C_{t+1}^{* p}$. This would reduce marginal utility of consumption at $t+1$. According to equation(16.a), this would increase the RHS. In order to maintain equality, the LHS of the equation has to go up, which would require $L_{t}^{p}$ to increase. Since the labor supply today depends on consumption tomorrow, the spenders are neither Rule-of-Thumb consumers, nor are they intra-temporal optimizers. They are simply credit constrained. This is a direct contrast from Mankiw(2000), Mankiw-Weinzierl (2005) and Yang(2007).

\subsection{Optimization of the firm}

The firms maximize their profit by choosing amount of aggregate capital and labor $K_{t}$ and $L_{t}$

$$
\begin{gathered}
\underset{\left\{K_{t}, L_{t}\right\}}{\operatorname{Max}}: K_{t}^{\alpha} L_{t}^{1-\alpha}-W_{t} L_{t}-r_{t} K_{t-1} \\
Y_{t}=K_{t-1}^{\alpha} L_{t}^{1-\alpha}
\end{gathered}
$$

The first order conditions for the firm determines the wage and the rental rate:

$$
\begin{gathered}
W_{t}=(1-\alpha) \frac{Y_{t}}{L_{t}} \\
r_{t}=\alpha \frac{Y_{t}}{K_{t-1}}
\end{gathered}
$$




\subsection{The Government}

The government collects taxes from the savers and the spenders, issues bonds,provides transfers and consumes part of the goods as government spending which is completely wasted or thrown away in the ocean. The government budget constraint looks like:

$$
R_{t-1}^{b} B_{t-1}+T R_{t}+G_{t}=T_{t}+B_{t}
$$

Where $T_{t}$ is the total tax collected defined as:

$$
\begin{gathered}
T_{t}=T_{t}^{l}+T_{t}^{k} \\
T_{t}^{l}=F * \tau_{t}^{L_{a}} W_{t} L_{t}^{a}+(1-F) * \tau_{t}^{L_{p}} W_{t} L_{t}^{p} \\
T_{t}^{k}=\tau_{t}^{k} r_{t} K_{t-1}
\end{gathered}
$$

Finally,the total transfer in the economy, $T R_{t}$ looks like:

$$
T R_{t}=T R_{t}^{a}+T R_{t}^{p}
$$

Where $T R_{t}^{a}, T R_{t}^{p}$ are aggregate transfers to the savers and the spenders, to be defined shortly.

The government also has to maintain intertemporal fiscal solvency. This will be achieved by using two conditions. First, any equilibrium must satisfy the Transversality conditions for the debt and capital accumulation:

$$
\begin{gathered}
E_{t} \lim _{T \longrightarrow \infty} \beta_{1}^{t+T} u^{\prime}\left(C_{t+T}^{* a}\right) B_{t+T}=0 \\
E_{t} \lim _{T \longrightarrow \infty} \beta_{1}^{t+T} u^{\prime}\left(C_{t+T}^{* a}\right) K_{t+T-1}=0
\end{gathered}
$$

Imposing the TVC on the flow budget constraint of the government, we derive the intertemporal budget constraint for the government:

$$
\frac{B_{t}}{Y_{t}}=s_{t}^{B}=\sum_{j=0}^{\infty} d_{t, t+j}\left[\begin{array}{c}
(1-\alpha) \tau_{t+j}^{L_{a}} \frac{F L_{t+j}^{a}}{L_{t+j}}+(1-\alpha) \tau_{t+j}^{L_{p}} \frac{(1-F) L_{t+j}^{p}}{L_{t+j}} \\
+\alpha \tau_{t+j}^{k}-s_{t+j}^{G}-s_{t+j}^{T R}
\end{array}\right]
$$

Where $L_{t}$ is the aggregate labor supply in the economy, to be defined later and $d_{t, t+j}=$ $\Pi_{i=o}^{j-1} R_{t+i}^{-1} \frac{Y_{t+i+1}}{Y_{t+i}}$. Equation(26) implies that the TVC condition for debt is satisfied.

Furthermore, following Leeper and Young(2006), the government uses different policy rules to adjust for any debt-financed tax cuts. The policy rules that the government uses are summarized as follows:

$$
\begin{aligned}
\ln \left(\frac{s_{t}^{T R^{a}}}{s^{T R^{a}}}\right) & =q_{T R^{a}} \ln \left(\frac{s_{t-1}^{B}}{s^{B}}\right), q_{T R^{a}} \leq 0 \\
\ln \left(\frac{s_{t}^{T R^{p}}}{s^{T R^{p}}}\right) & =q_{T R^{p}} \ln \left(\frac{s_{t-1}^{B}}{s^{B}}\right), q_{T R^{p}} \leq 0 \\
\ln \left(\frac{s_{t}^{G}}{s^{G}}\right) & =q_{G} \ln \left(\frac{s_{t-1}^{B}}{s^{B}}\right), q_{G} \leq 0
\end{aligned}
$$




$$
\begin{aligned}
\ln \left(\frac{\tau_{t}^{L_{a}}}{\tau^{L_{a}}}\right) & =q_{L_{a}} \ln \left(\frac{s_{t-1}^{B}}{s^{B}}\right), q_{L_{a}} \geq 0 \\
\ln \left(\frac{\tau_{t}^{L_{p}}}{\tau^{L_{p}}}\right) & =q_{L_{p}} \ln \left(\frac{s_{t-1}^{B}}{s^{B}}\right), q_{L_{p}} \geq 0 \\
\ln \left(\frac{\tau_{t}^{K}}{\tau^{K}}\right) & =q_{K}\left(\frac{s_{t-1}^{B}}{s^{B}}\right), q_{K} \geqslant 0
\end{aligned}
$$

\subsection{Aggregation}

The aggregate variables are defined as follows:

$$
\begin{gathered}
I_{t}=F * I_{t}^{a} \\
B_{t}=F * B_{t}^{a} \\
K_{t}=F * K_{t}^{a} \\
T R_{t}^{a}=F * t r_{t}^{a} \\
T R_{t}^{p}=(1-F) * t r_{t}^{p} \\
L_{t}=F * L_{t}^{a}+(1-F) * L_{t}^{p} \\
C_{t}=F * C_{t}^{a}+(1-F) * C_{t}^{p}
\end{gathered}
$$

The aggregate resource constraint looks like:

$$
C_{t}+I_{t}+G_{t}=Y_{t}
$$

In addition, we will define aggregate budget constraint for the savers and the spenders:

$$
\begin{gathered}
F C_{t}^{a}+I_{t}+B_{t}=\left(1-\tau_{t}^{k}\right) r_{t} K_{t-1}+\left(1-\tau_{t}^{L_{a}}\right) W_{t} F L_{t}^{a}+R_{t-1}^{b} B_{t-1}+T R_{t}^{a} \\
(1-F) C_{t}^{p}=\left(1-\tau_{t}^{L_{p}}\right) W_{t}(1-F) L_{t}^{p}+T R_{t}^{p}
\end{gathered}
$$

\subsection{Definition of Competitive equilibrium}

A competitive rational expectations equilibrium is defined as the agent's decisions, $\left\{C_{t}^{a, p}, L_{t}^{a, p}, K_{t}^{a}, B_{t}^{a}\right\}_{t=0}^{\infty}$, the firm's decisions, $\left\{L_{t}, K_{t}\right\}_{t=0}^{\infty}$, prices, $\left\{W_{t}, r_{t}\right\}_{t=0}^{\infty}$ and policy variables, $\left\{B_{t}, G_{t}, \tau_{t}^{K}, \tau_{t}^{L_{a}}, \tau_{t}^{L_{p}}, T R_{t}\right.$ \}$_{t=0}^{\infty}$, such that, given initial levels of capital and debt, $K_{t-1}$ and $B_{t-1}$, the optimality conditions for the different kinds of agents and firm's problems are solved; the goods, capital, labor and the bond markets clear; the transversality conditions for capital and debt hold; the government budget constraint and the policy rules(equations 28-33) and all the aggregate conditions(equations 34-43) are satisfied. We will only consider the ranges of the fiscal adjustment parameters- the q's- that are consistent with the existence of a rational expectations equilibrium. 


\subsection{Calibration and Solution Method}

An analytical solution of the model is not available; the equilibrium conditions are log-linearized around the original steady state growth path and analyzed in terms of percentage deviations from that steady state. The model is solved using Sims's(2001) algorithm. The model is calibrated at an annual frequency. Table 1 reports the benchmark values of parameters and the steady state values of variables before a permanent tax rate change. The choices of the values for structural parameters are comparable to McGrattan(1994) and Jones(2002) and are taken from Yang(2007), Leeper and Yang(2006), Joint Committee of Taxation(2006) and Burnside, Eichenbaum and Fischer(2005). The model implies that in the original steady state, the fraction of time spent on working is 0.2 , the consumption-output ratio is 0.63 , the investment-output ratio is 0.17 , the debt-output ratio in the original steady state before the tax cut is 0.376 , roughly corresponding to the ratio of federal debt held by the public to GDP in 2005[Table 78, economic report of the President(2006)]. Every version of the Saver-Spender must satisfy the above set of aggregate restrictions.

\subsection{Steady State of the system}

Using (19), (19.a),the steady state system looks like:

$$
\begin{gathered}
\left(C^{* a}\right)^{-\gamma_{1}}\left(1-\beta_{1} b_{1}\right)=\lambda^{a} \\
\chi^{a}\left(1-L^{a}\right)^{-\theta_{1}}=\lambda^{a}\left(1-\tau^{L_{a}}\right) \frac{Y}{L} \\
R^{k}=R^{b}=\frac{1}{\beta_{1}} \\
\left(C^{* p}\right)^{-\gamma_{2}}\left(1-\beta_{2} b_{2}\right)=\lambda^{p} \\
\chi^{p}\left(1-L^{p}\right)^{-\theta_{2}}=\lambda^{p}\left(1-\tau^{L_{p}}\right) \frac{Y}{L}
\end{gathered}
$$

In addition, we will need the following steady state version of the aggregate budget constraint for the spender and the aggregate resource constraint:

$$
\begin{gathered}
(1-F) C^{p}=\left(1-\tau^{L_{p}}\right) \frac{(1-F) L^{p}}{L} Y+T R^{p} \\
C+\delta K+G=Y
\end{gathered}
$$

\section{Dynamic Impacts of Tax rate cuts under alternative financing schemes}

In this section, we will analyze dynamic effects of various alternative financing schemes in response to a debt-financed tax cuts. We will compare our results between different versions of the SaversSpenders(SS from now) model and a modified version of Leeper and Young(2006, MLY from now) where we will hold the assumption of a representative agent but add internal habit persistence to his behavior. The different versions of the SS model will help us to identify the role of different kinds of heterogeneity on the dynamic behavior of the model. Table 2 summarizes the list of features and assumptions adopted by each version of the SS model. Model $\mathbf{1}$ is the baseline 
Saver-Spender model. where there is no additional heterogeneity. That means our model differs from the MLY model only by the existence of the credit constrained spenders. While solving for the initial steady state for the SS model, we explicitly impose the condition that both groups supply equal amount of labor, $L^{a}=L^{p}=0.2$ and no behavioral or preference heterogeneity. These assumptions are counter-factual,as was documented by Yang(2007). We impose these assumptions because this model is very similar to the Mankiw(2000) and the heterogenous model used in Mankiw and Weinzierl (2006). Furthermore, Gali, Salido and Valles(2004.a) explicitly uses this assumption. While Analyzing model 1, we will also report responses from the original Leeper and Yang(2006, OLY from now) model in addition to the MLY results. Model 2 is the SS model where there is preference heterogeneity. We will pose restrictions $\theta_{1}=1, \theta_{2}=2.0$, $\chi^{a}=2.721, \chi^{p}=2.543$. That means that the spenders and the savers in the SS model has intertemporal elasticity of leisure equal to 0.5 and 1.0, whether corresponding Frisch elasticities are 2 and 4 respectively. The saver has preference identical to the representative agent of the MLY model. The spenders also put less weight on leisure in their preference. This SS model produces a steady state wage of 0.7257 while the MLY model's wage rate is 0.8487 . The steady state interest rates are 0.2218 and 0.2179 respectively. Model 3 is the SS model with flexible labor supply. Here we retain all the parameter specification of the previous model but relax the counterfactual assumption of equal labor supply. We allow agents to endogenously choose their labor supply in the original steady state but still maintain the assumption of aggregate labor supply to be 0.2 . This original steady state produces $N^{L a}=0.2361, L^{p}=0.1458, W=0.8247$. The fact that saver's labor supply is greater than the spender is consistent with other papers ${ }^{2}$. The IES and the Frisch elasticity are identical to the Model 2. Model 4 is the full-fledged SS model outlined in the previous section with preference and tax heterogeneity. The savers have a larger marginal labor tax rate than the spender, following Yang(2007) and Jones(2002). With restriction on the aggregate labor supply, the original steady state produces $L^{a}=0.2828$ and $L^{p}=0.0758$. Therefore, spenders supply approximately half of the labor of the previous SS model. This will enable us to perfectly compare between the SS and MLY model without any ambiguity.

\subsection{Impulse Response Functions for a Capital Tax cut Financed by Transfers}

Figure 1 compares the effect of an unanticipated permanent cut of capital tax where the tax cut is financed by lump-sum transfers in model 1. That means policy rules (28) and (29) are operative. So, debt-financed deficits reduce expected future transfers to both groups. Fiscal adjustment parameters are summarized in Table 3. In the OLY model(dotted-dashed line), the tax cut has expansionary effect on output(tax base), with higher investment and hours worked along the transition path. Upon impact, a capital tax cut increases the after tax return on investment and the disposable income. This interest rate effect prompts the agent to substitute for more investment and less consumption. Lower consumption increases the marginal benefit of working, and with a higher elasticity of substitution, increasing labor supply. Output goes up and so does wage. After the permanent decline in capital tax, the agent faces the prospect of a declined transfer. The effect of future decline in the transfers is dominated by increase in income from investment and labor supply. As the economy converges to the new steady state, this combined wealth effect begins to dominate the substitution effect as the value of elasticity goes down, raising consumption and leisure. Labor supply and investment decreases somewhat, but remains above the original steady state. Although interest rate comes back to the original level, wage and output remains above the original level. Continued increase in the debt increases

\footnotetext{
${ }^{2}$ Other papers have dealt with the difference between the labor supply of the saver and spender in a different way. Yang(2007) assumes that the savers are more productive by introducing skill differences in her model. Although we refrain from doing so, our results are consistent with her work.
} 
interest payment and a permanently lower tax revenue keep net revenue(total revenue-net interest payment) permanently lower along the transition path. The picture is somewhat similar in the MLY model(solid line), with some exceptions. The introduction of habit persistence complicates the economic analysis of the transitional dynamics. Lags in consumption makes labor supply decisions more intertemporally dependent. For the representative agent, faced with habit, the tax cut creates smaller substitution effect, leading to smaller immediate increase in labor supply and investment. Consumption therefore, declines by a smaller amount because of the excess smoothness induced by habit. The immediate jump in output is also smaller for the same reason. Therefore, tax revenue and net revenue falls by slightly smaller amount. But since the habit persistence has only one period lag, the multiplier effect would be different between the models with and without habit persistence only in the short run, as could be inferred from Brown(1952). In the long run, as he pointed out, these differences disappear and we see very similar transition path for the OLY and MLY models. In the SS model(dashed line), the impulse response of the aggregate variables look very similar. But this model offers a different mechanics, as could be observed by the differences in the movement of relative prices. The saver exhibits similar behavior to the representative agent in the MLY model. But for the spender, the story is different. Since they do not accumulate capital, the tax cut does not have any direct impact on their disposable income. In face of the negative income effect of the future decline in transfer, the consumer will want to smooth consumption by the only instrument he has, by increasing labor supply. For him, labor supply decisions will follow strong intertemporal dependence. Habit persistence will play two roles. Saver will immediately reduce current consumption to smooth out consumption in future when they expect transfers to go down. Along the transition path, habit persistence will first induce steeper and then gradual increase in labor supply throughout the entire the transition path. This has an interesting effect on consumption. In the short run, steep increase in the labor supply will dominate the negative income effect from decline in the transfer, increasing consumption. But in the long run consumption will decline because of the lagged consumption effect,creating a hump-shape pattern and remaining above the original steady state. This however will allow the spender to enjoy more leisure, which is consistent with the flattening out of the labor supply in the long run. At the aggregate, the decline in the labor supply by the saver dominates the increase in labor supply by the spender, party because of the stronger wealth effect experienced by the former. Wages decline at the beginning, but continues to be above the original level, although always below the MLY model. Debt, interest payment, tax revenue and net revenue all exhibit very similar transition path compared to the MLY model.

Several important observations emerge from model 1. First, habit persistence does not add too much to the dynamic behavior of the agents along the transition path. It creates immediate and short differences with almost no long run consequences. It also helps to smooth out the transition path. Second, credit constraint alone does not alter the qualitative behavior in the aggregate. But if we look at the disaggregate level, we see significantly contrasting behavior from the saver and the spender. The reason why aggregate behavior is almost unchanged could stems from two factors. First, the fraction of the saver in our model is too small for them to overpower the savers in the aggregate impacts. Second, the behavior of the spenders, although different from the savers, is not contrasting enough to force the aggregate behavior in their favor. Their response could be enhanced by adding more heterogeneity to their behavior and we might see changes in the aggregate as well. This is what we will do in the next couple of models

Figure 2 compares the effect of an unanticipated permanent cut of capital tax financed by lump-sum transfer in model 2. The saver exhibits behavior similar to the previous model. Spender, with a smaller elasticity would leave labor supply almost unchanged while reducing consumption for compensation. This would rise the aggregate labor supply, but now smaller than the MLY model. Consumption for the spender rises quite dramatically in the short run while 
labor supply shows less dramatic increase, owning to a declined Frisch elasticity. The aggregate labor supply shows dramatically smaller decline in the short run because of the spender's more unwillingness to substitute labor both intra-temporarily and inter-temporarily. For the saver, the income effect from the capital tax cut dominate the substitution effect, causing consumption to go up and labor to go down further in the long run and in the new steady state. For the spender, after a brief increase, consumption peaks within the first 10 years and then shows dramatic decline in the longrun, falling even below the original steady state. The labor supply goes up in the longrun, but now smaller than the previous model. The aggregate labor supply is almost unchanged along the transition path, always being above the MLY case. The aggregate consumption is now below and investment is now above the MLY model. Higher investment and a higher labor supply allows output to be above the MLY model throughout the transition path and into the new steady state. Both tax revenue and Net tax revenue in the SS model are now higher than the MLY model. There appears to be small qualitative differences in the dynamic responses as well. Output, consumption, investment and net tax revenue all converge at the same rate between the two models while aggregate labor supply converges quicker in the SS model.The results are very similar in model 3 and do not report them ${ }^{3}$.

Figure 3 compares the effect of an unanticipated permanent cut of capital tax financed by lump-sum transfer in model 4. For the spender, they face a smaller marginal labor tax. Their after tax disposable income is therefore bigger than the previous SS models. A capital tax cut produces similar immediate effect in both MLY and SS model; consumptions go down a little bit, labor supply rapidly increases for saver because of the substitution effect, the increase now bigger than the previous SS model. With almost no immediate change in the wage, spender's labor supply is unchanged. A lower labor tax enables the spenders to enjoy a higher disposable income even with a lower labor supply. This helps them to overcome the negative income effect from the transfer cut and we see an increase in consumption in the short run, similar to the previous model. However, low elasticity forces the spenders to persistently increase their labor supply. Upon impact,after tax return on capital now increases less than the MLY model, raising investment by a lesser amount. Output rises, but falls below the MLY case. For the saver, the income effect starts to dominate very early and we see gradual decline in labor supply and increase in consumption, both along the transition path and to the new steady state. For spender, the gradual decline in transfer effects them more because they receive $70 \%$ of the transfer. As a result, the negative income effect will force them to reduce consumption in the short run, creating a hump-shape response. In the long run, consumption will decline further to a steady state similar to the previous model. The aggregate consumption is lower in the short run and goes slightly above the MLY model in the longrun. This allows the investment to lie below the MLY model in the short run but pushes above it in the long run. On the other hand, spenders continue to increase labor supply along the transition path. However, smaller elasticities force them to supply labor at a higher rate. As a result, the aggregate labor supply lies above the MLY case through out the transition path. Output goes above the MLY model in the long run. For the first time, we see the trend in debt/output ratio to deviate from the MLY model as a result of the movement in output. Tax revenue is way below the MLY model because of the smaller revenue collected from the spender, indicating a much more contractionary effect of the tax cut. Net revenue also lies below the MLY model. We notice three interesting things. First, there is an interesting interaction between habit persistence and elasticities. In the short run, habit persistence for the spender overpowers the lower elasticities in creating a substitution effect that leads to a more prolonged hump-shape response from the consumption of the spenders. In the longrun, lower elasticities overpower the habit persistence that sort of strengthens the negative

\footnotetext{
${ }^{3}$ The impulse response graph for model 3 is available upon request.
} 
income effect, creating a more dramatic decline in consumption for the spender. In the aggregate, total labor supply, output and consumption seems to under perform the MLY model while in the longrun, they over perform. Second, there are now substantial qualitative difference of the behavior from the fiscal variables. Third, response from both macro and fiscal variables appear to be smoother than the MLY model.

\subsection{Impulse Response Functions for a Labor Tax cut Financed by Transfers}

Figure 4 compares the effect of a permanent cut of labor tax in model 1 where the tax cut is financed by lump-sum transfers. In the OLY model, this has a expansionary effect, raising consumption, investment, labor supply and output. In the long run, the wealth effect motivates the agent to subside labor supply and investment. Consumption and output increases even further and output flattens out a bit. The effect on investment and therefore on output would be smaller compared to the capital tax cut case, both for the immediate effect and the transition path. Both remains above the original steady state. Debt and interest payment increases continuously along the transition path and both tax revenue and net revenue are below the original steady state. In the MLY model, we now see some interesting deviations. A decline in labor tax increases the after tax return on labor and substitution effect increases labor supply(reduce leisure) and consumption upon impact, although by smaller amount because of habit. The labor tax cut indirectly increases rental rate by increasing output. Investment jumps up, again by a smaller amount. The short run differences in the multiplier effect dies out very quickly and as the wealth effect begins to dominate, investment and labor supply subside a bit and converges to the long run steady state, being above the original one. Consumption and output again increases further but flattens out quickly to the new steady state. Convergence to the new steady state for consumption, output and labor supply is noticeably faster for the OLY model compared to the MLY model. Net tax revenue cosnsistently go down while remaining above the OLY model. In the SS model, the saver, again, exhibits similar behavior to the representative agent of the MLY model; consumption and labor supply jumps up upon impact. After that, consumption shows persistent increase to move to the new steady state while labor supply shows persistent decline to go below the original one. For the spender, the initial substitution effect is dominated by the income effect which prompts him to reduce labor supply a bit and increase consumption. Along the transition path, the decline in transfer weakens the income effect and forces him to increase his labor supply. Habit persistence coupled with the decline in the transfer creates a hump shape consumption response. At the aggregate,the initial jump in consumption is larger compared to the MLY model, stemming from the combined response from the saver and the spender. Aggregate labor supply and investment has a smaller upward jump, creating smaller jump in output. In the short run, investment shows a slower decline while labor supply exhibits a sharper increase. The latter converges to the new steady state faster and the former shows more persistence. Output also shows similar persistence while converging to the new steady state. As a result net revenue remains below the MLY case during most of the transition path.

Figure 5 compares the effect of labor tax cut financed by lump-sum transfer in model 2. For the saver, there is an immediate jump in labor supply and consumption. For the spender, the lower elasticity now produces stronger results, reducing labor supply and a smaller increase in consumption upon impact. With a lower IES, the decline in spender's labor supply is lower. With an immediate increase in after tax wage, saver's labor supply jumps up higher than the MLY case. This results in a larger increases in the initial labor supply. Lower Frisch elasticity on the other hand forces spenders to substitute less leisure for consumption and as a result, the initial increase in consumption is lower. In the short run, with almost no change in the real wage, the negative income effect from the reduced transfer forces the spender to rapidly increase his labor supply. This results in a short run increase in his consumption. Aggregate labor supply continues 
to increase dramatically and Output shoots up almost immediately above the MLY case. In the long run, spender's labor supply is less smooth compared to the previous model. Lower Frisch elasticity now allows for even smaller substitution between leisure and consumption, thereby reducing consumption. Aggregate output and investment remains above the MLY model while consumption is always below the MLY model. In the new steady state, spender's consumption goes down below the original steady state while saver's consumption is above the old one. Saver's labor supply almost comes back to the original steady state, while spender's labor supply is higher than the original steady state. Aggregate labor supply and output is much higher than the original steady state. Investment is slightly above and aggregate consumption is below the original steady state. We see significant qualitative and quantitative differences between the SS and the MLY model. Output is higher from the onset and the gap seems to widen in the new steady state. The aggregate labor supply shows remarkable contrast. Rather than going down in the short run, it shoots up even further the gap widens significantly in the new steady state. Tax revenue increases rapidly from the onset stays significantly higher than the MLY case. That means the tax cut is less contractionary in the SS model. However, because of similar interest rate and debt movement, the net tax revenue follows path similar to the MLY model, although staying above the latter throughout the transition path. Model 3 shows similar behavior as above and we do not report them.

Figure 6 compares the effect of an unanticipated $1 \%$ permanent cut of labor tax for both savers and the spenders financed by lump-sum transfer to both groups in model 4. Savers exhibit behavior identical to model 3. But for the spenders, a $1 \%$ decline in the labor tax now has a smaller substitution effect. Therefore, negative income effect dominates from the onset and we see a persistent decline in consumption throughout the transition path. As before, lower elasticities force the spenders to increase their labor supply throughout, similar to the previous SS model. But same pattern in their labor supply now produces less impact on the aggregate labor supply and we see that the total labor supply is below the MLY throughout the transition path, although showing similar pattern. Aggregate consumption is naturally below the MLY case. But with habit persistence, it looks flatter. Investment is below the MLY model throughout the transition. Lower investment leads to lower capital accumulation which coupled with a lower labor supply, forces output to be below the MLY model also. The decline in tax revenue is much greater, again indicating a much more contractionary effect of the tax cut. Net revenue also falls below the MLY model. Overall, the fiscal variables show qualitatively and quantitatively different behavior and the macro variables show response which are quantitatively different but qualitatively quite similar to the MLY model although more persistent.

\subsection{Impulse Response Functions of a Capital Tax cut Financed by Govern- ment Spending}

Figure 7 compares the effect of a permanent cut of capital tax where the tax cut is financed by reducing government-output ratio in model 1 . That means policy rule (30) is operative. In the OLY model, initial impact of the tax cut has effect on consumption, investment, output and labor supply similar to the transfer reduction case. But after that, the reduction in the government spending raises wealth by absorbing smaller share of the output. Wealthier household consumes more leisure, reducing labor supply along the transition path and in the new steady state. It also crowds in private consumption, raising consumption above its original steady state. On the other hand, an increase in the after tax return on capital raises investment which also raises steady state capital stock. This combined effect ultimately raises output in the new steady state, but now significantly lower than the transfer adjustment case. Wages fall below the original steady state while after tax return on capital comes back to the original steady state. An almost unchanged tax base coupled with a tax cut and increased debt reduces tax and net tax revenue 
along the transition path to a lower steady state. In the MLY model, there are very similar results. The jump in initial investment is lower because wealthy consumers, because of habit, reduces consumption only by a small amount, allocating less income in savings. The behavior of the rest of the economy follows the OLY model. In the SS model, the aggregate behavior also exhibits similar pattern. On the disaggregate level we again see contrasting behavior from the saver and the spender. For the saver, the wealth effect dominates along the entire transition path, allowing him to reduce his labor supply consistently. The spender initially increases labor supply with no change in consumption. In the short run, the crowding in effect increases his income, allowing him to enjoy more leisure and consumption. But in the long run, with wages rising, the substitution effect dominates the income effect and the spender increases his labor supply to a higher new steady state. But as was mentioned above, the fraction of the spender is small enough for the saver to dominate the spender in the aggregate, producing similar aggregate behavior compared to the MLY model.

Figure 8 compares the effect of a permanent cut of capital tax financed government spending in model 2. We see interesting results. The immediate effect of the tax cut is very similar to the previous model. In the short run, crowding in increases consumption for both agents and wealth effect reduces labor supply. In the long run, a higher wage now forces spenders to supply more labor. But because of lower Frisch elasticity, less leisure is substituted for consumption. Labor supply continues to increase but falls below the original steady for the spender. Labor supply for the saver continues to fall and the new steady state is lower than the old, although closer than the previous model. In the aggregate, we see a decline in the labor supply in the short run, although smaller because of the slower decline for the saver. Investment always stays above the MLY model because of the crowding in effect. Output continues to decline, but always above the MLY case because of the boost from relatively higher investment and aggregate labor supply. In the new steady state, output is somewhat above the original steady state, a contrast with the previous model while tax and net tax revenue are below the original steady state, although approximately $1 \%$ above the MLY model. Output, labor supply, investment, tax and net tax revenue all exhibit a fanning out effect; comparing with the MLY model, the longrun effect is more pronounced than the short run effect.

Figure 9 compares the effect of an unanticipated permanent cut of capital tax financed by government spending in model 3. This time the SS model produces response almost indistinguishable from the MLY model, a sharp contrast to model 2.

Why do we see dynamic behavior in model 3 very similar to the MLY while in model 2, there were sharp differences? The answer lies in the equal labor supply assumptions that we had in the previous model but relaxed in the present model. For the saver, analyzing transition from a steady state labor supply of 0.2361 instead of the counter-factual assumption of 0.2 significantly strengthens their dynamic response in the present model. For the spender,analyzing transition from a steady state labor supply of 0.1458 instead of 0.2 weakens their dynamic response. In the aggregate behavior, savers have larger fraction. Therefore, the dynamic behavior of the aggregate model follows their behavior, making it look very similar to a representative model . This model clearly shows the perils of using rule-of-thumb assumptions where the spenders follow the savers in their labor supply decisions because it can cause both underestimation and overestimation of responses for the two groups.

Figure 10 compares the effect of a permanent cut of capital tax financed government spending in model 4 . The response of the macro variables are very similar to the model 2 . This is because only the savers' responses are amplified. The total labor supply slightly is lower because of the reason mentioned in the previous subsection. Output therefore is also slightly below the MLY case. Debt/Output ratio is above the MLY case for the same reason. Tax revenue shows more negative impact, as expected and net revenue also falls below the MLY model. All the fiscal variables also exhibit fanning out effect. 


\subsection{Impulse Response Functions of a Labor Tax cut Financed by Government}

\section{Spending}

Figure 11 compares the effect of a permanent cut of labor tax where the tax cut is financed by reducing government-output ratio in model 1. In the OLY model, upon impact, consumption, output, labor supply and investment shows response similar to the transfer cut case. In the short run, lack of any significant interest rate effect combined with the crowding in effect reduces investment while consumption continues to increase. wealth effect also causes labor supply to go down, which coupled with a declined investment also reduces output. In the long run, the output, investment and labor supply all fall below their original steady state while consumption exhibits a persistent increase to a new and higher steady state. Tax and net tax revenue falls significantly below their original steady state. The MLY model exhibits identical behavior with respect to all the macro and fiscal variables concerned. The SS model too exhibits similar aggregate behavior. The saver mimics the representative agent in the MLY model . For the spender, the wealth effect from the crowding in and the reduced labor tax cut allows them to reduce their labor supply upon impact. But very quickly, the substitution effect starts to dominate the income effect and we see a rapid and then a persistent increase in the labor supply throughout the transition path to a new and higher labor supply. Higher labor supply allows them to enjoy a higher level of consumption everywhere along the transition path.

Figure 12 compares the effect of a permanent cut of labor tax financed by government spending in model 2. The immediate effect of the tax cut is similar to model 1. For both saver and the spender, the short run response in terms of consumption and labor supply is also similar. But in the long run, due to a lower IES and Frisch elasticity, the spender raises his labor supply very close to the original steady state, a contrast to the previous model while consumption shows similar level in the new steady state. The labor supply for the spender goes down in the new steady state, but now very close to the original steady state, another contrast. The aggregate labor supply remains above the MLY case, mainly due to saver's response. Investment is higher the MLY model. This forces output to be above the MLY model, although still below their own original steady state. The tax revenue, although declining, is higher than the MLY model, indicating a less contractionary effect of the tax cut. The fanning out effect of the aggregate variables again emerge, although less significant now. In model 3, we see impulse responses similar to the MLY model. The source of this contradiction with model 2 was explained in the previous section.

Figure 13 compares the effect of an unanticipated permanent cut of labor tax for both the saver and the spender financed by government spending in model 4. Again, the behavior of the saver is identical to the model 2. For the spenders, we see different response. The cut in the (lower) tax rate produces smaller substitute effect and with a decline in future government spending, labor supply goes down immediately, now more pronounced than model 2. Consumption takes an upward jump, but now quite smaller. In the short run, crowding in allows consumption go up rapidly but by a smaller amount. Lower elasticities force them to increase their labor supply persistently. In the long run, positive income effect from the crowding in is dominated by the effect from an increasingly lower substitutability between consumption and leisure and therefore, makes the transition path for consumption almost flat. In the new steady state, consumption is higher than the original one, but now significantly below the previous SS model. Their labor supply goes up to a higher labor in the new steady state. In the aggregate, consumption now falls below the MLY model. In the longrun and the new steady state, the gap is even bigger. Output, investment and total labor supply initially trails the MLY model, but eventually catches up in the new steady state. Tax revenue and net tax revenue shows very similar trend. 


\subsection{Impulse Response Functions of a Capital Tax cut Financed by Labor Tax}

Figure 14 compares the effect of a permanent cut of capital tax where the tax cut is financed by increasing the labor tax rate in model 1. As Leeper and Yang(2006) points out, this is an interesting experiment because one distortionary tax is somewhat replaced by another one. In the OLY model, the immediate effect is similar to other experiment with capital tax; consumption, goes down while investment, labor supply and output goes up. In the short run, positive income effect from reduced capital tax cut dominates the negative income effect from the labor tax increase and the combined positive wealth effect dominates substitution effect from the wage rate and the interest rate. Consumption increases somewhat but then goes down again. In the long run, the reduction in after tax return on labor dominates everything else. We see a decline in labor supply which reduces output. This reduces return on capital and investment goes down as well. Although investment and capital stock is higher in the new steady state, both labor supply and output dives below their original steady state. A lower output level coupled with a fixed government-output ratio unambiguously reduce consumption. For the fiscal variables, higher capital accumulation and a higher labor tax rate increases tax revenue in the new steady state. As Leeper and Yang(2006) pointed out, this increase in tax revenue should not be misunderstood as generated by a cut in capital tax alone. The net revenue, because of rising debt and interest payments, is always below the original steady state. The MLY model almost mimics the OLY model. The SS model also exhibits similar aggregate behavior. The saver's behavior is again comparable to the MLY model. The spender however, now shows different behavior. In the short run, habit persistence forces them to increase consumption even in the face of a future negative income effect. According to (16.a), a rise in consumption leads to a rise in future marginal utility from consumption which forces the spender to reduce their labor supply. After a while, decrease in consumption forces future marginal utility to reduce, asking spender to increase his labor supply a little bit. In the long run prolonged decline in consumption will persistently increase future marginal utility, making labor supply go down even in the new steady state. In model 2 and 3 , we see trend very similar to model 1 .

Figure 15 compares the effect of a permanent cut of capital tax in model 4 financed by a systematic increase in the labor tax on both groups, following rules from equations (31) and (32). Comparing with the previous SS model, we see fundamentally different response from both the macro and the fiscal variables. For the saver, the immediate effect of the capital tax cut increases labor supply,similar to the previous SS model. Their consumption decreases upon impact. In the very short run, income effect from the reduced capital tax cut dominates the negative income effect from an higher labor tax; consumption goes up even above their original steady state level. The negative income effect is larger because savers supply more labor and wages also go up. The negative income effect starts to dominate very quickly and consumption, after a brief increase, goes down. In the longrun and in the new steady state, we see a much larger decline in consumption. Labor supply however continues fall to a new steady state even lower than the model 2 or 3 . The effect on the spender is radically different. They do not experience any immediate tax cut; consumption remains unchanged upon impact while labor supply increases because of an immediate decline in wage that resulted from the upward movement in the interest rate. In the short run, an increase in the labor tax creates perplexing response. The substituting effect from a lower after tax wage interacts with habit persistence and lower elasticities forcing consumption to go up but also labor supply to go down as well. But the effect of habit wears down very quickly and wealth effect from labor tax increase forces consumption to go down and labor supply to go up. With a smaller tax rate, the negative wealth effect is smaller. But as the elasticities go down, we see a persistent increase in labor supply with a slower and smaller decline in consumption. In the new steady, consumption almost comes to the original steady state and labor supply is significantly above the original one, a phenomenon contrast to the 
previous SS model. However, lower labor supply by the saver(stronger, bigger actual decline) and a higher labor supply(weaker, smaller actual increase ) makes the total labor supply behave almost identical to the MLY case and therefore to the previous SS model, with labor supply overshooting the MLY model in the short run and undershooting in the longrun. Both output and investment overshoots the MLY case a bit in the short run and under shoots in the longrun. Tax revenue lies above the MLY model in the longrun, indicating a more expansionary effect of the tax cut. However, interest payments rise above the MLY model in the longrun. As a result. net revenue declines dramatically in the longrun, going far below the original steady state instead of going up, a trend contrast to the previous SS model. Therefore, this SS model produces dynamic response from the macro and fiscal variables which are qualitatively and quantitatively different and for some, opposite to the any previous version of the SS model.

\subsection{Impulse Response Functions of a Labor Tax cut Financed by Capital Tax}

Figure 16 compares the effect of a permanent cut of labor tax where the tax cut is financed by increasing the capital tax rate in model 1 . In the OLY model, the immediate effect is somewhat different. The after tax return on labor goes up, increasing labor supply somewhat. Investment is almost unchanged. Output increases slightly, increasing consumption. In the short run, expected decline in after tax return on capital because of the capital tax increase dramatically reduce investment. Reduced capital reduces output and consumption. Reduction in consumption is compensated by an increase in leisure which lowers labor supply. Consumption, labor supply, investment and output all go down in the new steady state. Tax and net revenue are both below their original steady state level. MLY model shows similar pattern. The SS model also shows similar aggregate behavior. The saver mimics the representative agent's behavior again. For the spender, we again see interesting and different behavior. Upon impact, labor supply always go down but consumption is almost unchanged. Along the transition path, consumption falls because of habit. Future increase in capital tax reduces capital accumulation which reduces output and wage. Spender, therefore, is forced to increases his labor supply throughout the transition path to the new steady state.

Figure 17 compares the effect of an unanticipated permanent cut of labor tax financed by capital tax in model 2. Surprisingly, this has very interesting and significantly different effect compared to model 1. With similar decline in the labor supply upon impact, the spender increases his labor supply lass dramatically than the previous SS model. But in the longrun the lower IES and Frisch elasticity causes him to increase his labor at a much higher steady state. On the other hand, the saver decreases his labor supply at a lower steady state than the previous model and his own original steady state. Consumption for both groups takes a similar dive to a lower steady state. In the aggregate we see a decline in the labor supply, which, with very similar movement in investment, reduces output slightly below the MLY model. The tax revenue, after an immediate decline, attempts to increase. But in the longrun, it takes a dramatic turn, declining further down to a much lower steady state. Net revenue also falls below the MLY case by a smaller margin. In model 3, we see impulse responses very similar to the MLY model, a direct contrast to model 2 .

Figure 18 compares the effect of an unanticipated permanent cut of labor tax for both the saver and the spender financed by capital tax increase in model 4. For the saver, the labor tax cut produces an immediate substitution effect, causing labor supply and consumption to up. Aggregate investment is almost unchanged upon impact and with a lower labor supply, output goes up a bit. In the short run and also in the longrun, the negative income effect from the capital tax rise dominates everything else and we see a gradual decline in consumption and investment. Labor supply also goes down in the steady state. Spender, on the other hand,responds immediately by reducing labor supply while lower elasticities prevent them from substituting for consumption, 
causing it to be unchanged. In the short run, aggregate output declines as a result of declined labor supply and investment. For the spender, the negative income from a declined wage starts to dominate the substitution effect and labor supply goes up. But with a lower elasticity and declined income, spender is forced to reduce consumption. In the longrun, consumption goes down even further to a much lower steady state, comparable to the previous SS model. Labor supply goes up in the new steady state, but now smaller than the previous SS model. Total labor supply goes down in the new steady state, but now slightly above the MLY model. Combined with a lower investment along the transition path and in the new steady state, output goes down, but now above the MLY case. Debt/output ratio falls below the MLY model because of the same reason. Tax revenue stays above the MLY model, indicating a less contractionary effect of the tax cut while net tax revenue lies above the MLY case as well, reflecting the same pattern. One sees quantitative differences among the SS and the MLY model, with little qualitative difference.

Several important observations emerge from this section. With preference heterogeneity, we now see qualitative and quantitative results in our heterogenous model which is significantly different from the representative agent model. First, preference heterogeneity amplifies the contrasting behavior in our model, producing different results. Second, behavioral heterogeneity not only distinguishes between the two groups, but also changes the result of the saver, who holds a larger fraction in the model and therefore, has a larger effect in the aggregate behavior. Third, behavioral heterogeneity not only produces short run differences, but also generates long run differences, which sometimes becomes more pronounced depending on which tax is cut and which adjustment is undertaken. Overall, behavioral heterogeneity appears to be important for dynamic and fiscal behavior of our macroeconomic model. After adding tax rate heterogeneity, the SS model produces results which are not only qualitatively and quantitatively different from the representative agent model, but they are also contrasting. Model 4 efficiently amplifies the contrasting behavioral difference between the saver and the spender and thereby, make the dynamic response the macro and fiscal variables sometimes fundamentally different. Second, from a policy perspective, this model highlights that some tax cut-adjustment schemes could be far more contractionary than a representative model would predict and some expansionary schemes could be much more expansionary. Third, this highly complicated model with its unique and more realistic interaction between habit, elasticity and tax structure produces dynamic response that appears to be much smoother and persistent than the representative agent model with habit persistence alone. Overall, this model clearly establishes the need and usefulness of using a heterogenous agent model in analysis of dynamic fiscal policy.

\section{Quantitative Significance of the Heterogenous Agent Model}

In the previous section, we have seen that the dynamic response of the RBC model with heterogeneity produces results which are different from the representative agent model. But how significant are these differences? In this section, we will try to answer this question by undertaking an experiment which will calculate dynamic and static scores of capital and labor tax rate cut under alternative financing schemes and try to investigate how much of the tax cut finances itself. This is the theme that has been followed in M\&W. For actual policy decisions about tax cuts, this same exercise is done by government agencies like Joint committee of taxation(1996, 2003,2005) and Congressional Budget Office(CBO,2005).

\subsection{Dynamic Scoring for different tax cuts under Alternative Financing schemes}

Following Joint Committee of Taxation(1996,2003), the static score for any particular tax cut can be written as: 


$$
\text { Static score }=(\tau+\Delta \tau) * Y-\tau * Y
$$

The dynamic score can be written as:

$$
\text { Dynamic score }=(\tau+\Delta \tau) *(Y+\Delta Y)-\tau * Y
$$

For model 1, 2,3 and for the MLY, the above equation simplifies to:

Static score at time $t$ after the tax cut $=\left[\left\{(1-\alpha) * Y * \tau_{t}^{L}\right\}+\left\{\alpha * Y * \tau_{t}^{K}\right\}\right]-T s s$

$$
\text { Dynamic score at time } t \text { after the tax cut }=T_{t}-T s s
$$

Where, Tss is the total tax revenue at the original steady state before the tax cut, defined in (22). For model 4, the static score equation is more complicated, but could be written as:

Static score at time $t$ after the tax cut $=\left[\left\{\begin{array}{c}(1-\alpha) * \frac{F L^{a} * Y}{L} \tau_{t}^{L_{a}} \\ +(1-\alpha) * \frac{(1-F) L^{p} * Y}{L} \tau_{t}^{L_{p}}\end{array}\right\}+\left\{\alpha * Y * \tau_{t}^{K}\right\}\right]-T s s$

Finally, the feedback effect, the effect that shows how much of the revenue impact of the tax cut is financed by higher growth or expansion of the tax base, is given by:

Feedback effect at time $t$ after the tax cut $=\left\{1-\frac{\text { Dynamic Score }}{\text { Static Score }}\right\} * 100$

Therefore, the feedback effect shows what percentage of the tax cut is paid for itself. Table 4 shows the dynamic feedback effect of a capital tax cut financed by alternative schemes at different point of time along the transition path. Column 1 shows the feedback effect when transfers adjust. This is the experiment conducted by M\&W. The baseline model of MLY is a discrete version of the $\mathrm{M} \& \mathrm{~W}$ model with habit persistence and can therefore, be compared with column 1 of table 1 in M\&W. The immediate feedback effect is $11.92 \%, 78.24 \%$ by the 25 th year and $79.54 \%$ in the new steady state. These numbers are somewhat different from the original M\&W model because of the habit persistence and different parameter specification ${ }^{4}$, but could nevertheless be compared. For model 1 with no heterogeneity and equal labor supply assumption, the feedback effects are $5.37 \%, 72.30 \%$ and $81.62 \%$ respectively. For model 2 with preference heterogeneity but equal labor supply assumption, the numbers are $27.93 \%, 116.24 \%$ and $124.23 \%$. For model 3 with preference heterogeneity and different labor supply assumption, the numbers are $25.91 \%, 83.46 \%$ and $85.95 \%$. Finally, for model 4 with preference and tax heterogeneity and no labor supply restriction, the numbers are $25.31 \%, 60.39 \%$ and $50.19 \%$. We notice some interesting features. For the baseline SS model of model 1, the immediate and short run effect is smaller than the MLY model. In the longrun, the feedback effect not only catches up with the MLY model, but appears to be more expansionary in the steady state(compare $80 \%$ to $82 \%$ ). For SS models with only preference heterogeneity, the entire transition path exhibits more expansionary effect of the tax cut. However, in the SS model with both preference and tax heterogeneity, the short run and immediate effect is larger while in the new steady state, appears to be less expansionary (compare $80 \%$ to 50\%). Column 2 shows the feedback effect when government spending adjusts. Model 1

\footnotetext{
${ }^{4}$ By changing the value of $\tau^{k}$ from 0.35 to 0.25 , increasing the value of $L$ from $20 \%$ to $34 \%$, reducing IES of consumption from 1 to 0.5 and assuming no habit persistence $(b=o)$, we get the MW model specification and can show the feedbacks are identical to their model.
} 
appears to be less expansionary than the MLY model. In the new steady state, model 1 shows the feedback effect is negative which means that reduction of output(tax base) contributes to $8.84 \%$ of the revenue loss, a number comparable to the MLY model. In model 2 , the immediate and short run feedback effect indicate much more expansionary effect. Within 25 years, it doubles the MLY case. In the new steady, the feedback effect is positive, indicating that capital tax cut financed by government spending could even be expansionary, which directly contrasts with the MLY model. In model 3, the feedback at the immediate and short run is much more expansionary than the MLY model $(20.64 \%$ and $50.60 \%$ compared to $6.64 \%$ and $22.52 \%$ ). Within 50 years, the feedback effect becomes negative, indicating a stronger contractionary effect of the tax cut. In the long run, feedback is negative and quite large(-26.42\% compared to $-8.84 \%)$, indicating that the representative model seriously underestimates the contractionary effect of the tax cut when financed by government spending, a trend that we also observed in the previous section. In model 4 , the feedback is negative and larger in the steady state, indicating an even larger underestimation of the contractionary effect of the tax cut. Therefore, table 3 clearly indicates the qualitative and quantitative implications of the heterogenous models when capital tax is cut.

Table 5 shows the dynamic feedback effect of a labor cut financed by alternative schemes at different point of time along the transition path. In case of the MLY, model 1, 2 and 3, the tax cut is a one percent reduction of labor tax which is same for all groups. In model 4, the labor tax cut is a $1 \%$ reduction of the labor tax imposed on both the saver and the spender. Column 1 shows the feedback effect when labor tax is financed by transfer, an experiment conducted by M\&W. In the MLY model, the immediate effect is $0.41 \%, 12.50 \%$ by 25 th year and $12.59 \%$ in the new steady state. The immediate effect is considerable smaller than the $\mathrm{M} \& \mathrm{~W}$, although their results could easily be derived by changing the parameters and removing the habit persistence. The steady state feedback effect could be compared with $\mathrm{M} \& \mathrm{~W}$ model, indicating very little role of habit in the feedback calculations or in the long run dynamic behavior, a point highlighted in the previous section. In model 1, the immediate feedback is negative, indicating a contractionary effect which contrasts with the MLY model. In the short run, the feedback becomes positive by 25 th year. In the new steady state, the feedback is $14.3 \%$, almost comparable to the MLY model. In model 2, the immediate feedback is $11.8 \%$, quite large compared to the MLY model. In the short run, the feedback effects are noticeably higher(almost double). In the steady state, the feedback is $45.2 \%$, almost three times than the MLY model. In model 3, the immediate feedback is $4.3 \%$. In the short run and in the new steady state, the feedback is roughly $22 \%$, almost twice the MLY model. In model 4 , the immediate effect is $5.2 \%$. In the short run, the feedback increases from almost $7 \%$ after one year to $5.6 \%$ in the 25 th year. In the next 25 year, the feedback dramatically decreases until in the new steady state it becomes $-2 \%$, suggesting a mild contractionary effect of the tax cut where the other models suggested otherwise. This experiment suggests dramatically different results in the SS model contingent on alternative heterogeneity. Short run effects appear to be more expansionary than the MLY model(with exception of model 1 where we see contractionary effect). In the longrun, the expansionary effects are magnified even more(with the exception of model 4, where we see contractionary effects). Column 2 shows feedback effect when government spending adjusts. We see contractionary effect across all the models. In the MLY model, feedback contracts from $-4.2 \%$ upon impact to $-44.6 \%$ in the new steady state. In model 2 we see a bigger immediate and short run impact(-11\% and -8.8\%) but smaller steady state feedback($43 \%$ ) compared to the MLY model(-44.6\%), indicating slightly less contractionary effect of the tax cut. In model 2 , immediate feedback effect is even positive(8.1\%), indicating expansionary effect of the tax cut. In the long run, however, the feedback effect contracts to $-34.47 \%$ in the new steady state, indicating a less contractionary effect of the tax cut. In model 3, the immediate effect is negative but very small(-0.14\%). After one year, the feedback becomes positive to $2.2 \%$. In the short run however, the feedback effect becomes negative until it becomes $-52 \%$ in the new steady state, indicating a more contractionary effect of the tax cut. In model 4 , the immediate 
feedback effect is $-2.8 \%$. But in the new steady state it becomes $-56.55 \%$, suggesting a much more contractionary effect of the tax cut than any other model. This experiment also shows interesting results under different models; Short run effects are dramatically mixed, ranging from strongly contractionary to expansionary. In the longrun, feedback effects consistently suggest more contractionary effect in the SS models compared to the MLY model. Column 3 shows the feedback effect when capital tax adjusts. In the MLY model, the immediate effect is $-9.56 \%$, $-15 \%$ after one year, then $116.38 \%$ after 25 th year and finally $102 \%$ in the new steady state. In model 1, the immediate effect is more contractionary(-16\%). But in the new steady state, the feedback appears to be very similar to the MLY model. In model 2, the immediate effect is smaller(-1\%) and the longrun effect is larger(103.86\%). In model 3, the feedback are very much comparable to the MLY model, an issue documented in the previous section. In model 4, the immediate effect is more contractionary $(-13.16 \%)$, but the longrun feedback is comparable to the MLY model(103\%). Therefore, table 4 clearly indicates the qualitative and quantitative importance of the heterogenous models when labor tax is cut because they provide a wide array of different and sometimes contrasting results.

Several important observations emerge from this section. While the feedback results strengthen our claim about the usefulness of the SS models in the dynamic calculations, they also provide further insight into the complicated nature of the results from the tax experiments and their dependence on the interactions between behavior of the heterogeneous groups. We notice some general features of our quantitative results. The SS model unambiguously intensifies the dynamic behavior of the aggregate model, making experimental results more dramatic. In case of contractionary policies, the SS model predicts more contractionary effects than the representative agent model. The underestimation by the representative agent model can be as high as $23 \%$ for the capital tax cut and $8 \%$ for a labor tax cut. Similarly, when the policies are expansionary, the SS model predicts a more expansionary effect on the economy. The underestimation by the representative agent model can be as high as $45 \%$ for the capital tax cut and $33 \%$ for a labor tax cut. Therefore, these model highlight the importance of using heterogenous agent models in important policy making considerations. The qualitative results from the SS also suggests a wider menu of possible outcomes which could also be relevant for analyzing the efficacy of certain fiscal reforms.

\section{$6 \quad$ Steady State Analysis}

This section will look at the effect of alternative fiscal policies with their various adjustment rules on the steady state dynamics of various versions of the SS models. There are two objectives. First, we will analytically analyze the steady state comparative statics results of the SS model and compare those with the representative agent model. Second, we will conduct numerical exercises to analyze the steady state effects of various fiscal policies and their alternative adjustments. These results will also be compared and contrasted between the SS and the MLY model.

\subsection{Comparative Statics}

In this section, we will derive steady state comparative results for the SS model under very general CES utility function and CRS production function to highlight the universality of the results obtained. Following Leeper and Yang(2006), let us define a general production function $F($.$) and express it in terms of the capital-labor ratio, k$. Let

$$
z=\frac{k}{L}, f(z)=\left(\frac{k}{L}\right)^{\alpha}
$$

So, 


$$
\begin{gathered}
y=F(k, L)=L f(z) \\
F_{L}(k, L)=(1-\alpha) f(z) \\
F_{L}(k, L)=(1-\alpha) f(z) \\
F_{k}(k, L)=\alpha \frac{f(z)}{z}
\end{gathered}
$$

Also define the steady state marginal utility from consumption and labor in general notations to be $u^{\prime}\left(C^{a, p}(1-b)\right)$ and $v^{\prime}\left(1-L^{a, p}\right)$. Then rewrite the steady state versions of equations (system of equations can be re-written as

$$
\begin{aligned}
& v^{\prime}\left(1-L^{a}\right)=u^{\prime}\left(C^{a}\left(1-b_{1}\right)\right)\left(1-\beta_{1} b_{1}\right)\left(1-\tau^{L_{a}}\right)(1-\alpha) f(z) \\
& v^{\prime}\left(1-L^{p}\right)=u^{\prime}\left(C^{p}\left(1-b_{2}\right)\right)\left(1-\beta_{2} b_{2}\right)\left(1-\tau^{L_{p}}\right)(1-\alpha) f(z)
\end{aligned}
$$

Also write the steady state version of equation (10)

$$
\frac{1}{\beta_{1}}-(1-\delta)=\alpha\left(1-\tau^{K}\right) \frac{f(z)}{z}
$$

Next rewrite the aggregate resource constraint of equation (50) in terms of $s^{G}$ and $z$ as

$$
F * C^{a}+(1-F) C^{p}=L\left[\left(1-s^{G}\right) f(z)-\delta z\right]
$$

The remaining equations of the system are

$$
\begin{gathered}
(1-F) C^{p}=\left(1-\tau^{L_{p}}\right)(1-\alpha) \frac{(1-F) L^{p}}{L} Y+T R^{p} \\
L=F * L^{a}+(1-F) * L^{p} \\
T R=T R^{a}+T R^{p}
\end{gathered}
$$

For our fiscal experiments, we define net tax revenue as

$$
N R=T R-\left(R^{b}-1\right) B
$$

Axiom 1 To carry out comparative statics experiments for model 1, 2 and 3, we assume $\tau_{t}^{L_{a}}=$ $\tau_{t}^{L_{p}} \forall t$.

Proposition 2 Under the assumption of axiom 1, the sign of $\frac{\partial L^{p}}{\partial \tau^{L}}$ is ambiguous. We see

$$
\frac{\partial L^{p}}{\partial \tau^{L}} \prec 0 \text { iff } C^{p} \succ \gamma_{2}\left(\frac{(1-\alpha)\left(1-\tau^{L}\right) L^{p} Y}{L}\right)
$$


Proof. See Appendix-A

Let us give the intuition for the results. The term within the parentheses on the right hand side of the inequality is the wage income of the spender. As long as spender's consumption is greater than a fraction of his wage income, a fraction determined by the IES for consumption, income effect would dominate the substitution effect, allowing the spender to reduce labor supply when labor tax goes up and vice versa.

Proposition 3 Under the assumption of axiom 1, the sign of $\frac{\partial L^{a}}{\partial \tau^{L}}$ is ambiguous. We see

$$
\frac{\partial L^{a}}{\partial \tau^{L}} \prec 0 \text { iff } 1 \succ \frac{\gamma_{1}(1-F)\left(1-\tau^{L}\right)}{C^{a} F}\left\{\left[\left[W\left(1-\tau^{L}\right)-\frac{C}{L}\right] \frac{B}{A}-\left\{(1-\alpha) L^{p} f(z)\right\}\right]\right\} 0
$$

Where $B$ and $A$ are constants defined as

$$
B=\frac{1}{\theta_{2}}\left[\frac{-\left(1-L^{p}\right)}{\left(1-\tau^{L}\right)}+\frac{(1-\alpha) f(z) L^{p}\left(1-L^{p}\right) \gamma_{2}}{C^{p}}\right]
$$

and

$$
A=\left[1+\frac{(1-\alpha)\left(1-\tau^{L}\right) f(z)\left(1-L^{p}\right) \gamma_{2}}{C^{p} \theta_{2}}\right]
$$

Proof. See Appendix-A

Proposition 3 shows that the labor supply decisions of the saver depends on a restriction which is a function of our model's deep parameters and observed data. It is difficult to provide any economic intuition behind proposition 2 and rightfully so. For the spender, it was easier to explain his labor supply decisions because he faces only decisions between consumption and labor supply. Taxes effect both of these decisions directly. For the saver, however, taxes have both direct and indirect effects. The direct effect comes from the euler equation of labor supply. But there is an indirect effect which comes from the aggregate resource constraint where the availability of consumption for the saver depends on how much is consumed by the spender. This second general equilibrium effect ${ }^{5}$ prevents us from analytically specifying saver's labor supply decisions. From proposition 2 and 3, it is easy to show that the sign of $\frac{\partial L}{\partial \tau^{L}}$ ambiguous. This is a direct contradiction to the analytical results obtained by Leeper and Yang(2006), where the sign of the derivatives in (79) was unambiguous, negative. Therefore it provides a glimpse to the crucial differences between the representative agent model and our heterogenous agent model.

Proposition 4 Under the assumption of axiom 1, the sign of $\frac{\partial L^{p}}{\partial T R}$ is unambiguous. We see

$$
\frac{\partial L^{p}}{\partial T R} \prec 0
$$

Proof. See Appendix-A

Proposition 5 Under the assumption of axiom 1, the sign of $\frac{\partial L^{a}}{\partial T R}$ is ambiguous. We see

\footnotetext{
${ }^{5}$ Papers that use complicated heterogenous models such as Imrhohoglu(1999) and Rios-Riul(1997) argues that many of dynamic response of the agents come from interaction between them and is very difficult to quantify. They refer to these effects as General Equilibrium Effects.
} 


$$
\frac{\partial L^{a}}{\partial T R} \prec 0 \text { iff } \frac{\left(1-L^{a}\right) \gamma_{1}}{C^{a} F}\left[\frac{1}{(1-F)}\left\{\frac{C}{L}-\left(1-\tau^{L}\right) W\right\}-W\left(1-\tau^{L}\right)\right] \succ 1
$$

Proof. See Appendix-A

Combining proposition 4 and 5 , we can easily show that the sign of $\frac{\partial L}{\partial T R}$ is ambiguous. This is a direct contradiction to one of the basic results in a representative agent RBC model where there are lump sum transfers. In representative agent model, as Leeper and Yang(2006) points out, transfers are distributionaly neutral and non-distorting. As a result, transfers do not effect labor supply decisions. In our SS model, the spender's labor supply decision is directly effected. For the saver, transfers change the distribution of income and effect their marginal labor supply decisions as well.

Proposition 6 Under the assumption of axiom 1

$$
\frac{\partial L^{a}}{\partial S^{G}} \succ 0, \frac{\partial L^{p}}{\partial S^{G}}=0
$$

Proof. See Appendix-A

From Proposition 8, we can easily show that $\frac{\partial L}{\partial S^{G}} \succ 0$. This is consistent with Leeper and Yang(2006). This is because changing government spending does not create any distributional effects. Hence the effect of government spending is similar between the MLY and the SS model.

Proposition 7 In the SS model

$$
\frac{\partial K}{\partial \tau^{K}} \prec 0
$$

Proof. See Appendix-A

Proposition 9 is also consistent with Leeper and Yang(2006). This is because only the savers accumulate capital. Capital tax effects only their investment. Since the savers behave very similar to the representative agent, the effect of capital tax on capital accumulation is very similar between the SS and MLY model.

Proposition 8 In the SS model

$$
\frac{\partial K}{\partial T R}=\text { Ambiguous }
$$

Proof. The proof is easy and follows directly from corollary 7.

Combining Proposition 2,3,4,5,8,9 and using the definition of net revenue from equation(77), we can easily show that the signs of $\frac{\partial Y}{\partial \tau^{L}}, \frac{\partial Y}{\partial T R}, \frac{\partial(N R)}{\partial \tau^{L}}, \frac{\partial(N R)}{\partial T R}$ are all ambiguous. This again is a direct contradiction with Leeper and Yang(2006).

\subsection{Numerical Experiments}

Comparative statics from the previous section point out the ambiguity of the steady state dynamics under alternative policy changes. In order to fully understand how policies effect the steady state dynamics, we will take our fully calibrated MLY and the SS model analyze alternative policy effects. We will only use the model-3 as our chosen SS model. We could also analyze the model-4. But the steady state dynamics become very complicated with tax heterogeneity. Therefore, analyzing model-3 is sufficient to appreciate the role of heterogeneity. 
Following Leeper and $\operatorname{Yang}(2006)$ and using the assumption of no tax heterogeneity for model3 , the steady state intertemporal budget constraint could be written as follows

$$
\left(1-\beta^{-1}\right) \Delta S^{B}=\Delta S^{G}+\Delta S^{T R}-(1-\alpha) \Delta \tau^{L}-\Delta d \tau^{K}
$$

When we want to see the effect of a capital tax cut, we set $\Delta d \tau^{K}=-0.0035$ and when we want to see the effect of labor tax cut, we set, $\Delta d \tau^{K}=-0.0025$.It is straightforward to use (78) to compute the adjustment required in other instruments as a function of the posited change in debt, $\Delta S^{B}$. Figure 19 summarizes the relationship between the debt-output ratio and various budgetary variables for three distorting fiscal adjustments under the benchmark parameter values of table 1 when there is a $1 \%$ capital tax cut. The x-axis in each of the nine plots has debt-output ratios in the new steady state varying from 0.376 to 1.0. The offsetting policy used is labeled at the y-axis of the first row. The first row reports the magnitudes of fiscal instruments in levels in the new steady state. The second and last rows plot percent changes in the tax base and net revenues relative to their levels in the original steady state with no tax cut and debt-output ratio of 0.376. Similar to Leeper and Yang(2006), we see that a higher debt-output ratio in the MLY model is associated with (1) larger required fiscal adjustments from, (2) less favorable expansionary effects with unchanged tax base for the transfer-adjustment case and (3) more costly tax cuts in terms of a larger decline in the tax revenue. These results are consistent with out previous results. A higher debt-ratio induces a larger fraction of government resources to be devoted to debt servicing. This requires either both government and transfers to be permanently lower or labor tax to be permanently higher. All of the above adjustments, as pointed out in section 3, has contractionary effects . Larger adjustments will have larger distortions, forcing a larger decline in both tax base and net revenue. In the SS, model however, the picture is different. Government spending adjustment and labor tax increase appears to be less contractionary, partly because of a favorable labor supply response from the spender as was explained in section. The net revenue also appears to be decreasing less. When transfers adjust, we see very contrasting response between the MLY and the SS model. In the MLY model, transfers have no effect on the tax base. In the SS model, a decline in the transfers creates a negative wealth effect which forces the spenders to increase their labor supply, causing an expansion of the tax base. With unfavorable movement in the interest rate, the net revue also goes down, but now significantly smaller than the MLY model. Figure 20 summarizes the relationship between the debt-output ratio and various budgetary variables for three distorting fiscal adjustments under the benchmark parameter values of table 1 when there is a $1 \%$ labor tax cut. Very similar picture emerge in this case with tax base decreasing less than the MLY model and appearing to be expansionary when transfers adjust. The net revenue appears to be decreasing less under all adjustments.

\section{Conclusions}

As Leeper and Yang(2006) pointed out, dynamic scoring is a complex business. This paper has made a vigorous attempt to enrich our understanding of the complex effect of various fiscal policies. From our viewpoint, this paper has made several contribution to the existing literature. First, we have developed a modified version of the savers-spenders model which could provide a unified framework that could be used to study both the aggregate and distributional aspects of fiscal policy. Second, we have expanded Leeper and Yang(2006)'s study of the dynamic impact of various tax cuts under alternative financing schemes in a heterogenous agent environment. Our study indicates that the dynamic aggregate response of the heterogenous agent model differs from the aggregate response of their representative agent model quantitatively and sometimes qualitatively. Third, we have extended Congressional Budget Office (2005), Joint Committee of 
Taxation(2005) and Mankiw and Weinzierl(2006)'s approach to dynamic scoring calculation with a much broader menu of policies and have shown that there could be significant quantitative and even qualitative difference between our calculations and theirs. Finally, by using a convenient yet restricted heterogenous agent model, we have shown the relative importance of adopting a dynamic approach to tax/debt burden analysis which has not yet been extensively studied in the literature, but deserves fullest attention. Future work could look at the distributional aspects of the dynamic fiscal policy with much greater detail. But the message of the paper is clear; It is essential to use macroeconomic models which entail some degree of realistic heterogeneity among its agents for the important purpose of policy making as well to carry out meaningful research. 


\section{References}

Altig, D., A. J. Auerbach, L. J. Kotlikoff, K. A. Smetters, and J. Walliser (2001): "Simulating Fundamental Tax Reform in the United States," American Economic Review, June, 574-95.

Altonji, J. G. (1986): "Intertemporal Substitution in Labor Supply: Evidence from Micro Data," Journal of Political Economy, 94(3), S176-S215.

Auerbach, A. J., and Kotlikoff, L., J. (1987): "Dynamic Fiscal Policy". Cambridge University Press, Cambridge, MA.

Auerbach, A. J. (2005): "Dynamic Scoring: An Introduction to the Issues," American Economic Review, May 2005, 421-425.

Bohn, Henning. (1998): "The Behavior of U.S. Public Debt and Deficits", The Quarterly Journal of Economics, August1998, 949-963.

Baxter, M., and R. G. King (1993): "Fiscal Policy in General Equilibrium," American Economic Review, 86, 1154-1174.

Bruce, N., and S. J. Turnovsky (1999): "Budget Balance, Welfare, and the Growth Rate: 'Dynamic Scoring' of the Long-Run Government Budget," Journal of Money, Credit and Banking, 31(2), 162-186.

Burnside, C., M. Eichenbaum, and J. D. M. Fisher (2000): "Assessing the Effects of Fiscal Shocks," NBER Working Paper No. 7459.

Chung, Hess., Leeper, Eric, M (2007): "What Has Financed Government Debt?", CAEPR Working Paper\# 2007-015, Indiana University.

Campbell, J. Y., and N. G. Mankiw (1989): "Consumption, Incomes, and Interest Rates: Reinterpreting the Time Series Evidence," in NBER Macroeconomics Annual 1989, ed. by O. J. Blanchard, and S. Fischer, pp. 185-216. MIT Press.

Congressional Budget Office (2005): "Analyzing the Economic and Budgetary Effects of a 10 Percent Cut in Income Tax Rates," CBO, Washington, D.C., December 1.

Constantinides, G. C. (1990), "Habit Formation: A Resolution of the Equity Premium Puzzle," Journal of Political Economy 98: 519-43.

Economic Report of the President (2006):United States Government Printing Office, Washington, D.C.

Erceg, C. J., L. Guerrieri, and C. J. Gust (2005): "Expansionary Fiscal Shocks and the Trade Deficit,"

Forni, L., L. Monforte, and L. Sessa (2006): "Keynes vs. Ricardo: Revisiting the Effects of Fiscal Policy in an Estimated DSGE Model for the Euro Area," Manuscript, Bank of Italy.

Furman, J. (2006): "A Short Guide to Dynamic Scoring," Center for Budget and Policy Priorities, August 24.

Gali, J., J. D. Lopez-Salido, and J. Valles (2003): "Understanding the Effects of Government Spending on Consumption," Mimeo, Bank of Spain.

Gordon, D. B., and E. M. Leeper (2005): "Are Countercyclical Fiscal Policies Counterproductive?," NBER Working Paper No. 11869.

Harberger, A. C. (1962): "The Incidence of the Corporation Income Tax," Journal of Political Economy, 70, 215-40.

Heathcote, Jonathan. (2005): "Fiscal Policy with Heterogeneous Agents and Incomplete Markets", Review of Economic Studies, January 2005, 72, p. 161-188

Heathcote, Jonathan., and Domeij, David. (2004): "On the Distributional Effects of Reducing Capital Taxes" International Economic Review, May 2004, 45/2, p. 523-554

Joint Committee on Taxation (2005): "Macroeconomic Analysis of Various Proposals to Provide $\$ 500$ Billion in Tax Relief," JCT, U.S. Congress, Washington, D.C., (JCX-4-05), March 1. 
Joint Committee on Taxation (2005): "Overview of Revenue Estimating Procedures and Methodologies Used by the Staff of the Joint Committee on Taxation". February 2, Washington, DC.

Jones, J. B. (2002): "Has Fiscal Policy Helped Stabilize the Postwar U.S. Economy?," Journal of Monetary Economics, 49(May), 709-746.

King, R. G., and S. Rebelo (1999): "Resuscitating Real Business Cycles," in Handbook of Macroeconomics, Volume 1B, ed. by J. B. Taylor, and M. Woodford, pp. 927-1007. Elsevier, Amsterdam.

King, R. G., C. I. Plosser, and S. T. Rebelo (2002): "Production, Growth and Business Cycles: Technical Appendix," Computational Economics, 20(1-2), 87-116.

Kotlikoff, L., J., and Jokisch, Sabine. (2007): "Simulating the Dynamic Macroeconomic Effects of the FairTax", The National Tax Journal, 2007

Lustig, Hanno., Sleet, Chris., and Yeltekin, Sevin(2007): "Does the US Government Hedge Against Expenditure Risk?", Mimeo, Unversity of California, Los Angles.

Leeper, E. M., S. -C. S. Yang (2006): " Dynamic Scoring: Alternative Financing Schemes", forthcoming in Journal of Public Economics, NBER Working Paper No. 12103

Mankiw, N. G., and M. Weinzierl (2006): "Dynamic Scoring: A Back-of-the- Envelope Guide," Journal of Public Economics, 90 (8-9)

McGrattan, E. R. (1994): "The Macroeconomic Effects of Distortionary Taxation," Journal of Monetary Economics, 33(3), 573-601.

Novales, A., and J. Ruiz (2002): "Dynamic Laffer Curves," Journal of Economic Dynamics and Control, 27(2), 181-206.

Otrok, C., B. Ravikumar, and C. Whiteman (2002), "Habit Formation: A Resolution of the Equity Premium Puzzle?" Journal of Monetary Economics 49: 1261-1288.

Poterba, James, M. (1988): " Are Consumers Forward Looking? Evidence from Fiscal Experiments," American Economic Review 78 (May 1988), 413-418.

Piketty, Thomas., and Saez, Emmanuel (2007): "How Progressive is the U.S. Federal Tax System? A historical and International Perspective", Journal of Economic Perspectives, Volume 21, Number 1, Winter 2007, Pages 3-24.

Shapiro, Matthew D., and Slemrod, Joel. (1995): "Consumer Response to the Timing of Income:Evidence From a Change in Tax Withholding," American Economic Review 85 (March 1995), pp. 274-283.

Sims, C. A. (2001): "Solving Linear Rational Expectations Models," Journal of Computational Economics, 20(1-2), 1-20.

Trabandt, M., and H. Uhlig (2006): "How Far Are We From the Slippery Slope? The Laffer Curve Revisited," SFB 649 Discussion Paper 2006-023, Humboldt University.

Wolff, Nathan, Edward. (1998): "Recent Trends in the Size Distribution of Household Wealth", Journal of Economic Perspectives, Vol. 12, No. 3, Summer 1998, pp. 131-150

Wolff, Nathan, Edward. (2001): "Recent Trends in Wealth Ownership, from 1983 to 1998", in Thomas M. Shapiro and Edward N. Wolff eds., Assets for the Poor: The Benefits of Spreading Asset Ownership, Russell Sage Press, 2001, pp. 34-73.

Yang, Shu-Chun, Susan.(2007): "Do Capital Income Tax Cuts Trickle Down?" National Tax Journal, 60(3),551-567. 


\section{Appendix-A}

\section{Proof of Proposition 2}

Under assumption 1, The steady state system in section is as follows

$$
f(z)=\left(\frac{k}{L}\right)^{\alpha}
$$

so that

$$
\begin{gathered}
y=F(k, L)=L f(z) \\
F_{L}(k, L)=(1-\alpha) f(z) \\
W=F_{L}(k, L)=(1-\alpha) f(z) \\
r=F_{k}(k, L)=\alpha \frac{f(z)}{z} \\
v^{\prime}\left(1-L^{a}\right)=u^{\prime}\left(C^{a}\left(1-b_{1}\right)\right)\left(1-\beta_{1} b_{1}\right)\left(1-\tau^{L}\right)(1-\alpha) f(z) \\
v^{\prime}\left(1-L^{p}\right)=u^{\prime}\left(C^{p}\left(1-b_{2}\right)\right)\left(1-\beta_{2} b_{2}\right)\left(1-\tau^{L}\right)(1-\alpha) f(z)
\end{gathered}
$$

Also write the steady state version of equation (10)

$$
\frac{1}{\beta_{1}}-(1-\delta)=\alpha\left(1-\tau^{K}\right) \frac{f(z)}{z}
$$

Next rewrite the aggregate resource constraint of equation (50) in terms of $s^{G}$ and $z$ as

$$
C=F * C^{a}+(1-F) C^{p}=L\left[\left(1-s^{G}\right) f(z)-\delta z\right]
$$

The remaining equations of the system are

$$
\begin{gathered}
(1-F) C^{p}=(1-F)(1-\alpha)\left(1-\tau^{L}\right) L^{p} f(z)+T R^{p} \\
L=F * L^{a}+(1-F) * L^{p} \\
T R=T R^{a}+T R^{p}
\end{gathered}
$$

Total differentiating (a.6) and simplifying,

$$
d L^{a}=\frac{\left\{-(1-\alpha) u^{\prime}\left(C^{a}\left(1-b_{1}\right)\right)\left(1-\beta_{1} b_{1}\right) f(z)\right\}}{\left\{v^{\prime}\left(1-L^{a}\right)\right\}}\left[\frac{-1}{\left(1-\tau^{L}\right)} d \tau^{L}+\frac{f^{\prime}(z)}{f(z)} d z+\frac{u^{\prime}(.)\left(1-b_{1}\right)}{u^{\prime}(.)} d C^{a}\right]
$$

Now

$$
f^{\prime}(z)=\frac{\alpha f(z)}{z}
$$


Substituting (a.15) and multiplying both the numerator and denominator of the RHS of (a.14) by $\left(1-L^{a}\right)$ and also making use of (a.6), (a.14) could be written as

$$
d L^{a}=\frac{v^{\prime}(.)}{\left(1-L^{a}\right) v^{\prime}(.)}\left[\frac{-\left(1-L^{a}\right)}{\left(1-\tau^{L}\right)} d \tau^{L}+\frac{\left(1-L^{a}\right) \alpha}{z} d z+\frac{u^{\prime}(.)\left(1-b_{1}\right)}{u^{\prime}(.)} d C^{a}\right]
$$

Now

$$
\frac{1}{\theta_{1}}=\frac{-v^{\prime}(.)}{\left(1-L^{a}\right) v^{\prime}(.)}=I E S \text { for leisure of the saver }
$$

and

$$
\gamma_{1}=\frac{-u^{\prime}(.)\left(1-b_{1}\right) C^{a}}{u^{\prime}(.)}=I E S \text { for consumption of the saver }
$$

Using (a.17) and (a.18), equation (a.16) can be rewritten:

$$
d L^{a}=\frac{1}{\theta_{1}}\left[\frac{-\left(1-L^{a}\right)}{\left(1-\tau^{L}\right)} d \tau^{L}+\frac{\left(1-L^{a}\right) \alpha}{z} d z-\frac{\left(1-L^{a}\right) \gamma_{1}}{C^{a}} d C^{a}\right]
$$

Similarly for the spender, we can get

$$
d L^{p}=\frac{1}{\theta_{2}}\left[\frac{-\left(1-L^{p}\right)}{\left(1-\tau^{L}\right)} d \tau^{L}+\frac{\left(1-L^{p}\right) \alpha}{z} d z-\frac{\left(1-L^{p}\right) \gamma_{2}}{C^{p}} d C^{p}\right]
$$

Total differentiating ARC, equation(a.9)

$$
\begin{aligned}
F * d C^{a}+(1-F) d C^{p=} & {\left[\left(1-s^{G}\right) f(z)-\delta z\right] d L } \\
& +L\left[\left(1-s^{G}\right) f^{\prime}(z)-\delta\right] d z-L f(z) d s^{G}
\end{aligned}
$$

Total differentiating budget constraint of the spender, equation(a.10)

$$
\begin{aligned}
d C^{p}= & (1-\alpha)\left(1-\tau^{L}\right) f(z) d L^{p}+(1-\alpha)\left(1-\tau^{L_{p}}\right) L^{p} f^{\prime}(z) d z \\
& -(1-\alpha) L^{p} f(z) d \tau^{L}+\frac{d T R^{p}}{(1-F)}
\end{aligned}
$$

Substitute (a.22) into (a.20) and re-arrange

$$
\begin{aligned}
& d L^{p} \overbrace{\left[1+\frac{(1-\alpha)\left(1-\tau^{L}\right) f(z)\left(1-L^{p}\right) \gamma_{2}}{C^{p} \theta_{2}}\right]}^{A}=\overbrace{\frac{1}{\theta_{2}\left[\frac{-\left(1-L^{p}\right)}{\left(1-\tau^{L}\right)}+\frac{(1-\alpha) f(z) L^{p}\left(1-L^{p}\right) \gamma_{2}}{C^{p}}\right]}}^{B} d \leftarrow \Psi) \\
& +\overbrace{\frac{1}{\theta_{2}}\left[\frac{\left(1-L^{p}\right) \alpha}{z}-\frac{(1-\alpha) f^{\prime}(z) L^{p}\left(1-L^{p}\right) \gamma_{2}}{C^{p}}\right]}^{C_{-} C^{C}} d z \\
& -\overbrace{\left\{\frac{\left(1-L^{p}\right) \gamma_{2}}{\theta_{2} C^{p}(1-F)}\right\}}^{D} d T R^{p}
\end{aligned}
$$

From (a.20) we see 


$$
\frac{\partial d L^{p}}{d \tau^{L}}=\frac{B}{A}
$$

So,

$$
\frac{\partial d L^{p}}{d \tau^{L}} \prec 0 \text { iff } \frac{B}{A} \prec 0
$$

The denominator, $A$, is positive. So the sign of $\frac{\partial d L^{p}}{d \tau^{L}}$ depends on the numerator. So

$$
\begin{gathered}
\frac{\partial d L^{p}}{d \tau^{L}} \prec 0 \text { iff } B \prec 0 \\
\Rightarrow \operatorname{iff} \frac{1}{\theta_{2}}\left[\frac{\left(1-L^{p}\right)}{\left(1-\tau^{L}\right)}-\frac{(1-\alpha) f(z) L^{p}\left(1-L^{p}\right) \gamma_{2}}{C^{p}}\right] \succ 0 \\
\Rightarrow \operatorname{iff} C^{p} \succ \gamma_{2}\left(1-\tau^{L}\right)(1-\alpha) f(z) L^{p}
\end{gathered}
$$

Using equation(a.2) on the right hand side, the inequality could be written as

$$
\Rightarrow \frac{\partial d L^{p}}{d \tau^{L}} \prec 0 \text { iff } C^{p} \succ \gamma_{2}\left(1-\tau^{L}\right)(1-\alpha) \frac{Y}{L} L^{p}
$$

\section{Proof of Proposition 3}

Substitute (a.22) into (a.21)

$$
\begin{aligned}
F * d C^{a}= & {\left[\left(1-s^{G}\right) f(z)-\delta z\right] d L } \\
& +L\left[\left(1-s^{G}\right) f^{\prime}(z)-\delta\right] d z-L f(z) d s^{G} \\
& -(1-F)\left[\begin{array}{c}
+(1-\alpha)\left(1-\tau^{L_{p}}\right) L^{p} f^{\prime}(z) d z-(1-\alpha) L^{p} f(z) d \tau^{L}
\end{array}\right]-d T R^{p}
\end{aligned}
$$

Also from (a.11)

$$
d L=F * d L^{a}+(1-F) * d L^{p}
$$

substituting (a.24) and Re-organizing

$$
\begin{aligned}
F * d C^{a}= & {\left[\left(1-s^{G}\right) f(z)-\delta z-(1-\alpha)\left(1-\tau^{L}\right) f(z)\right](1-F) d L^{p} } \\
& +\left[L\left\{\left(1-s^{G}\right) f^{\prime}(z)-\delta\right\}-\left\{(1-F)(1-\alpha)\left(1-\tau^{L_{p}}\right) L^{p} f^{\prime}(z)\right\}\right] d z \\
& +\left\{(1-F)(1-\alpha) L^{p} f(z)\right\} d \tau^{L}-\{L f(z)\} d s^{G}-d T R^{p} \\
& +\left[F\left\{\left(1-s^{G}\right) f(z)-\delta z\right\}\right] d L^{a}
\end{aligned}
$$

Substituting (a.20) into (a.23) and reorganizing,

$$
\begin{aligned}
F * d C^{a}= & {\left[\begin{array}{c}
\left.\left[\left(1-s^{G}\right) f(z)-\delta z-(1-\alpha)\left(1-\tau^{L}\right) f(z)\right](1-F) \frac{B}{A}\right] d \tau^{L} \\
+\left\{(1-F)(1-\alpha) L^{p} f(z)\right\}
\end{array}\right] } \\
& +\left[\begin{array}{c}
{\left[\left(1-s^{G}\right) f(z)-\delta z-(1-\alpha)\left(1-\tau^{L}\right) f(z)\right](1-F) \frac{C_{-} C}{A}} \\
-\left[L\left\{\left(1-s^{G}\right) f^{\prime}(z)-\delta\right\}-\left\{(1-F)(1-\alpha)\left(1-\tau^{L_{p}}\right) L^{p} f^{\prime}(z)\right\}\right]
\end{array}\right] d z \\
& -\left[\left[\left(1-s^{G}\right) f(z)-\delta z-(1-\alpha)\left(1-\tau^{L}\right) f(z)\right](1-F) \frac{D}{A}+1\right] d T R^{p} \\
& -\{L f(z)\} d s^{G}+\left[F\left\{\left(1-s^{G}\right) f(z)-\delta z\right\}\right] d L^{a}
\end{aligned}
$$


Substituting (a.25) into (a.19) and reorganizing,

$$
\begin{aligned}
& \overbrace{\left[1+\frac{\left(1-L^{a}\right) \gamma_{1}}{\theta_{1} C^{a} F}\left\{\left[F\left\{\left(1-s^{G}\right) f(z)-\delta z\right\}\right]\right\}\right]}^{E} d L^{a}
\end{aligned}
$$

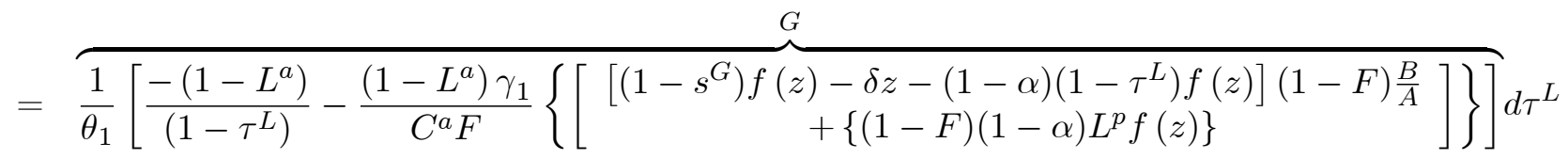

$$
\begin{aligned}
& H \\
& +\frac{1}{\theta_{1}\left[\frac{\left(1-L^{a}\right) \alpha}{z}-\frac{\left(1-L^{a}\right) \gamma_{1}}{C^{a} F}\left\{\left[\begin{array}{c}
{\left[\left(1-s^{G}\right) f(z)-\delta z-(1-\alpha)\left(1-\tau^{L}\right) f(z)\right](1-F) \frac{C_{-} C^{A}}{A}} \\
+\left[\begin{array}{c}
L\left\{\left(1-s^{G}\right) f^{\prime}(z)-\delta\right\} \\
-\left\{(1-F)(1-\alpha)\left(1-\tau^{L_{p}}\right) L^{p} f^{\prime}(z)\right\}
\end{array}\right]
\end{array}\right\}\right.\right.} d z \\
& +\overbrace{\frac{1}{\theta_{1}}\left[\frac{\left(1-L^{a}\right) \gamma_{1}}{C^{a} F}\left\{\left[\left(1-s^{G}\right) f(z)-\delta z-(1-\alpha)\left(1-\tau^{L}\right) f(z)\right](1-F) \frac{D}{A}+1\right\}\right]}^{M} d T R^{p} \\
& +\overbrace{\frac{1}{\theta_{1}\left[\frac{\left(1-L^{a}\right) \gamma_{1}}{C^{a} F}\{L f(z)\}\right]}}^{X-X} d s^{G}
\end{aligned}
$$

Simplifying

$$
d L^{a}=\frac{G}{E} d \tau^{L}+\frac{H}{E} d z+\frac{M}{E} d T R^{p}+\frac{X_{-} X}{E} d s^{G}
$$

From (a.27), we see

$$
\frac{\partial L^{a}}{\partial \tau^{L}} \prec 0 \text { iff } \frac{G}{E} \prec 0
$$

From (a.27), we see the denominator $E$ is a positive number. Therefore

$$
\begin{gathered}
\frac{\partial L^{a}}{\partial \tau^{L}} \prec 0 \text { iff } G \prec 0 \\
\Rightarrow \quad \frac{1}{\theta_{1}}\left[\frac{\left(1-L^{a}\right)}{\left(1-\tau^{L}\right)}+\frac{\left(1-L^{a}\right) \gamma_{1}}{C^{a} F}\left\{\left[\begin{array}{c}
\left.\left.\left[\left(1-s^{G}\right) f(z)-\delta z-(1-\alpha)\left(1-\tau^{L}\right) f(z)\right](1-F) \frac{B}{A}\right]\right\} \\
+\left\{(1-F)(1-\alpha) L^{p} f(z)\right\}
\end{array}\right] \succ 0\right.\right. \\
\Rightarrow \quad \frac{1}{\left(1-\tau^{L}\right)}+\frac{\gamma_{1}(1-F)}{C^{a} F}\left\{\left[\begin{array}{c}
\left.\left(1-s^{G}\right) f(z)-\delta z-(1-\alpha)\left(1-\tau^{L}\right) f(z)\right] \frac{B}{A} \\
+\left\{(1-\alpha) L^{p} f(z)\right\}
\end{array}\right]\right\} 0
\end{gathered}
$$

After substituting values from (a.9) and (a.4), we see

$$
\frac{\partial L^{a}}{\partial \tau^{L}} \prec 0 \text { iff } 1 \succ \frac{\gamma_{1}(1-F)\left(1-\tau^{L}\right)}{C^{a} F}\left\{\left[\left[W\left(1-\tau^{L}\right)-\frac{C}{L}\right] \frac{B}{A}-\left\{(1-\alpha) L^{p} f(z)\right\}\right]\right\} 0
$$

\section{Proof of Proposition 5}

From (a.20), we see that spender's labor supply only gets effected by their only transfers. Therefore, we can write

$$
\frac{\partial L^{p}}{\partial T R}=\frac{\partial L^{p}}{\partial T R^{p}} \frac{\partial T R^{p}}{\partial T R}=\frac{\partial L^{p}}{\partial T R^{p}} \cdot 1
$$


Substituting from (a.20)

$$
\frac{\partial L^{p}}{\partial T R}=\frac{D}{A}
$$

Since $A$ is a positive constant and $D$ is a negative one, we can unambiguously write

$$
\frac{\partial L^{p}}{\partial T R} \prec 0
$$

\section{Proof of Proposition 6}

From (a.32), we see

$$
\frac{\partial L^{a}}{\partial T R}=\frac{\partial L^{a}}{\partial T R^{p}} \frac{\partial T R^{p}}{\partial T R}=\frac{\partial L^{p}}{\partial T R^{p}} \cdot 1
$$

Substituting the value of $\frac{\partial L^{p}}{\partial T R^{p}}$

$$
\frac{\partial L^{a}}{\partial T R}=\frac{M}{E}
$$

We see that $E$ is unambiguously positive. Therefore substituting values from (a.2), (a.4) and (a.9) and also values of $D$ and $A$ from (a.23) and re-organizing we can show

$$
\frac{\partial L^{a}}{\partial T R} \prec 0 \text { iff } \frac{\left(1-L^{a}\right) \gamma_{1}}{C^{a} F}\left[\frac{1}{(1-F)}\left\{\frac{C}{L}-\left(1-\tau^{L}\right) W\right\}-W\left(1-\tau^{L}\right)\right] \succ 1
$$

\section{Proof of Proposition 8}

From (a.23), we can readily see that $\frac{\partial L^{p}}{\partial S^{G}}=0$. Again, from From (a.33) we see that both $X_{-} X$ and $E$ are positive constants. Therefore,

$$
\frac{\partial L^{p}}{\partial S^{G}} \succ 0
$$

Combining the above two results, we can easily see that, $\frac{\partial L}{\partial S^{G}} \succ 0$.

\section{Proof of Proposition 9}

Total differentiate (a.8), the euler equation for capital

$$
\left\{\alpha(\alpha-1)\left(1-\tau^{K}\right) \frac{f(z)}{K * z}\right\} d K+\left\{\alpha(1-\alpha)\left(1-\tau^{K}\right) \frac{f(z)}{L * z}\right\} d L-\left\{\frac{f(z)}{z}\right\} d \tau^{K}=0
$$

From (a.36), it is clear that

$$
\frac{\partial K}{\partial \tau^{K}}=\frac{\left\{\frac{f(z)}{z}\right\}}{\left\{\alpha(\alpha-1)\left(1-\tau^{K}\right) \frac{f(z)}{K * z}\right\}} \prec 0
$$

This is because the numerator is positive while the denominator is negative. 


\begin{tabular}{|l|l|l|l|l|l|}
\hline Parameter & Value & Parameter & Value & Parameter & Value \\
\hline$\alpha$ & 0.36 & $S^{T R}$ & 0.07 & $L$ & 0.2 \\
$\beta_{1}=\beta_{2}$ & 0.96 & $S^{T R_{a}}$ & $0.7 * S^{T R}$ & $\tau^{L_{a}}$ & 0.25 \\
$V$ & 0.70 & $S^{T R_{p}}$ & $0.3 * S^{T R}$ & $\tau^{L_{p}}$ & 0.096 \\
\hline$\gamma_{1}=\gamma_{2}$ & 1 & $S^{G}$ & 0.2 & $\tau^{K}$ & 0.35 \\
\hline$b_{1}=b_{2}$ & 0.6 & $S^{C}$ & 0.63 & $F$ & 0.60 \\
\hline$\theta_{1}=\theta_{2}$ & 1 & $S^{B}$ & 0.17 & $\chi^{a}$ & 2.721 \\
\hline & & $\delta$ & 0.1 & $\chi^{p}$ & 2.543 \\
\hline
\end{tabular}

Table 1: Benchmark Parameter values

\begin{tabular}{|l|l|l|}
\hline Model & Features & Assumptions \\
\hline Model 1 & No preference Heterogeneity & $\gamma_{1}=\gamma_{2}=1, \theta_{1}=\theta_{2}=1, \chi^{a}=\chi^{p}=2.721$ \\
& Equal labor supply & $L^{a}=L^{p}=0.2$ \\
& No Tax Heterogeneity & $\tau^{L_{a}}=\tau^{L_{p}}=\tau^{L}=0.25$ \\
\hline Model 2 & Yes preference Heterogeneity & $\gamma_{1}=\gamma_{2}=1, \theta_{1}=1, \theta_{2}=2, \chi^{a}=2.721, \chi^{p}=2.543$ \\
\hline & Equal labor supply & $L^{a}=L^{p}=0.2$ \\
\hline & No Tax Heterogeneity & $\tau^{L_{a}}=\tau^{L_{p}}=\tau^{L}=0.25$ \\
\hline Model 3 & Yes preference Heterogeneity & $\gamma_{1}=\gamma_{2}=1, \theta_{1}=1, \theta_{2}=2, \chi^{a}=2.721, \chi^{p}=2.543$ \\
\hline & No equal labor supply & Flexible labor supply \\
\hline & No Tax Heterogeneity & $\tau^{L_{a}}=\tau^{L_{p}}=\tau^{L}=0.25$ \\
\hline Model 4 & Yes preference Heterogeneity & $\gamma_{1}=\gamma_{2}=1, \theta_{1}=1, \theta_{2}=2, \chi^{a}=2.721, \chi^{p}=2.543$ \\
\hline & No equal labor supply & Flexible labor supply \\
\hline & Yes Tax Heterogeneity & $\tau^{L_{a}}=0.25, \tau^{L_{p}}=0.096$ \\
\hline
\end{tabular}

Table 2: Specification for model 1, 2, 3, 4. Unless mentioned in the table, the rest of the parameters in table 1 would be valid

\begin{tabular}{|l|l|l|}
\hline Adjustment Parameter & Values \\
\hline & $\Delta \tau^{K}=-1 \%$ & $\Delta \tau^{L_{a}}=\Delta \tau^{L_{p}}=\Delta \tau^{L}=-1 \%$ \\
$q_{G}$ & -0.119 & -0.130 \\
$q_{K}$ & & 0.206 \\
\hline$q_{T R^{a}}$ & -0.341 & -0.371 \\
\hline$q_{T R^{p}}$ & -0.341 & -0.371 \\
\hline$q_{L_{a}}$ & 0.149 & \\
\hline$q_{L_{p}}$ & 0.149 & \\
\hline
\end{tabular}

Table 3: Fiscal Adjustment Parameters under various policy rules 


\begin{tabular}{|c|c|c|c|c|}
\hline \multirow[t]{2}{*}{ Models } & \multirow[t]{2}{*}{ Time Horizon } & \multicolumn{3}{|c|}{ Fiscal Adjustment } \\
\hline & & Transfers & Government Spending & Labor Tax \\
\hline \multirow[t]{5}{*}{ Baseline Model } & Immediate Impact & 11.92 & 6.64 & 13.75 \\
\hline & 1 year & 15.24 & 7.92 & 16.30 \\
\hline & 25 year & 78.40 & 25.97 & 42.02 \\
\hline & 50 year & 79.53 & 7.24 & 61.15 \\
\hline & Steady State & 79.54 & -8.84 & 70.71 \\
\hline \multirow[t]{5}{*}{ Model 1} & Immediate Impact & 5.37 & 2.04 & 8.55 \\
\hline & 1 year & 7.62 & 2.82 & 9.47 \\
\hline & 25 year & 72.30 & 22.52 & 44.68 \\
\hline & 50 year & 78.03 & 6.23 & 61.61 \\
\hline & Steady State & 81.62 & -8.22 & 70.64 \\
\hline \multirow[t]{5}{*}{ Model 2} & Immediate Impact & 27.93 & 23.75 & 30.57 \\
\hline & 1 year & 31.03 & 25.19 & 33.89 \\
\hline & 25 year & 116.24 & 50.60 & 46.63 \\
\hline & 50 year & 120.89 & 25.55 & 70.38 \\
\hline & Steady State & 124.23 & 4.65 & 79.85 \\
\hline \multirow[t]{5}{*}{ Model 3} & Immediate Impact & 25.91 & 20.64 & 31.22 \\
\hline & 1 year & 27.36 & 20.28 & 33.50 \\
\hline & 25 year & 83.46 & 19.66 & 48.14 \\
\hline & 50 year & 85.26 & -5.62 & 67.37 \\
\hline & Steady State & 85.95 & -26.42 & 76.31 \\
\hline \multirow[t]{5}{*}{ Model 4} & Immediate Impact & 25.31 & 16.24 & 36.12 \\
\hline & 1year & 25.79 & 15.12 & 38.11 \\
\hline & 25 year & 60.39 & 9.19 & 46.70 \\
\hline & 50 year & 57.45 & -12.00 & 68.82 \\
\hline & Steady State & 50.19 & -31.62 & 80.87 \\
\hline
\end{tabular}

Table 4: Dynamic Feedback effect along the transition path of Capital tax cut while others adjust. Column 3-5 shows percent of static revenue impact offset by higher growth. 


\begin{tabular}{|c|c|c|c|c|}
\hline \multirow[t]{2}{*}{ Models } & \multirow[t]{2}{*}{ Time Horizon } & \multicolumn{3}{|c|}{ Fiscal Adjustment } \\
\hline & & Transfers & Government Spending & Capital Tax \\
\hline \multirow[t]{5}{*}{ Baseline Model } & Immediate Impact & 0.41 & -4.23 & -9.56 \\
\hline & 1 year & 3.23 & -3.20 & -14.97 \\
\hline & 25 year & 12.50 & -25.01 & 116.38 \\
\hline & 50 year & 12.59 & -36.77 & 104.79 \\
\hline & Steady State & 12.59 & -44.59 & 102.14 \\
\hline \multirow[t]{5}{*}{ Model 1} & Immediate Impact & -8.54 & -11.10 & -15.96 \\
\hline & 1 year & -4.71 & -8.88 & -21.46 \\
\hline & 25 year & 6.98 & -27.50 & 116.73 \\
\hline & 50 year & 11.17 & -36.77 & 104.87 \\
\hline & Steady State & 14.26 & -42.91 & 102.17 \\
\hline \multirow[t]{5}{*}{ Model 2} & Immediate Impact & 11.83 & 8.11 & -1.08 \\
\hline & 1 year & 17.49 & 11.97 & -2.77 \\
\hline & 25 year & 40.06 & -8.42 & 118.47 \\
\hline & 50 year & 43.03 & -24.12 & 106.95 \\
\hline & Steady State & 45.15 & -34.47 & 103.85 \\
\hline \multirow[t]{5}{*}{ Model 3} & Immediate Impact & 4.40 & -0.14 & -7.87 \\
\hline & 1 year & 8.74 & 2.26 & -11.66 \\
\hline & 25 year & 21.12 & -25.71 & 116.50 \\
\hline & 50 year & 22.05 & -41.69 & 105.17 \\
\hline & Steady State & 22.68 & -52.02 & 102.48 \\
\hline \multirow[t]{5}{*}{ Model 4} & Immediate Impact & 5.26 & -2.81 & -13.16 \\
\hline & 1year & 6.98 & -2.59 & -20.14 \\
\hline & 25 year & 5.69 & -32.02 & 118.82 \\
\hline & 50 year & 1.70 & -46.70 & 106.14 \\
\hline & Steady State & -2.10 & -56.53 & 103.22 \\
\hline
\end{tabular}

Table 5: Dynamic Feedback effect along the transition path of Labor tax cut while others adjust. Column 3-5 shows percent of static revenue impact offset by higher growth. 
Figure 1:Response to Capital Tax Shock:Transfers Adjust(Model 1)
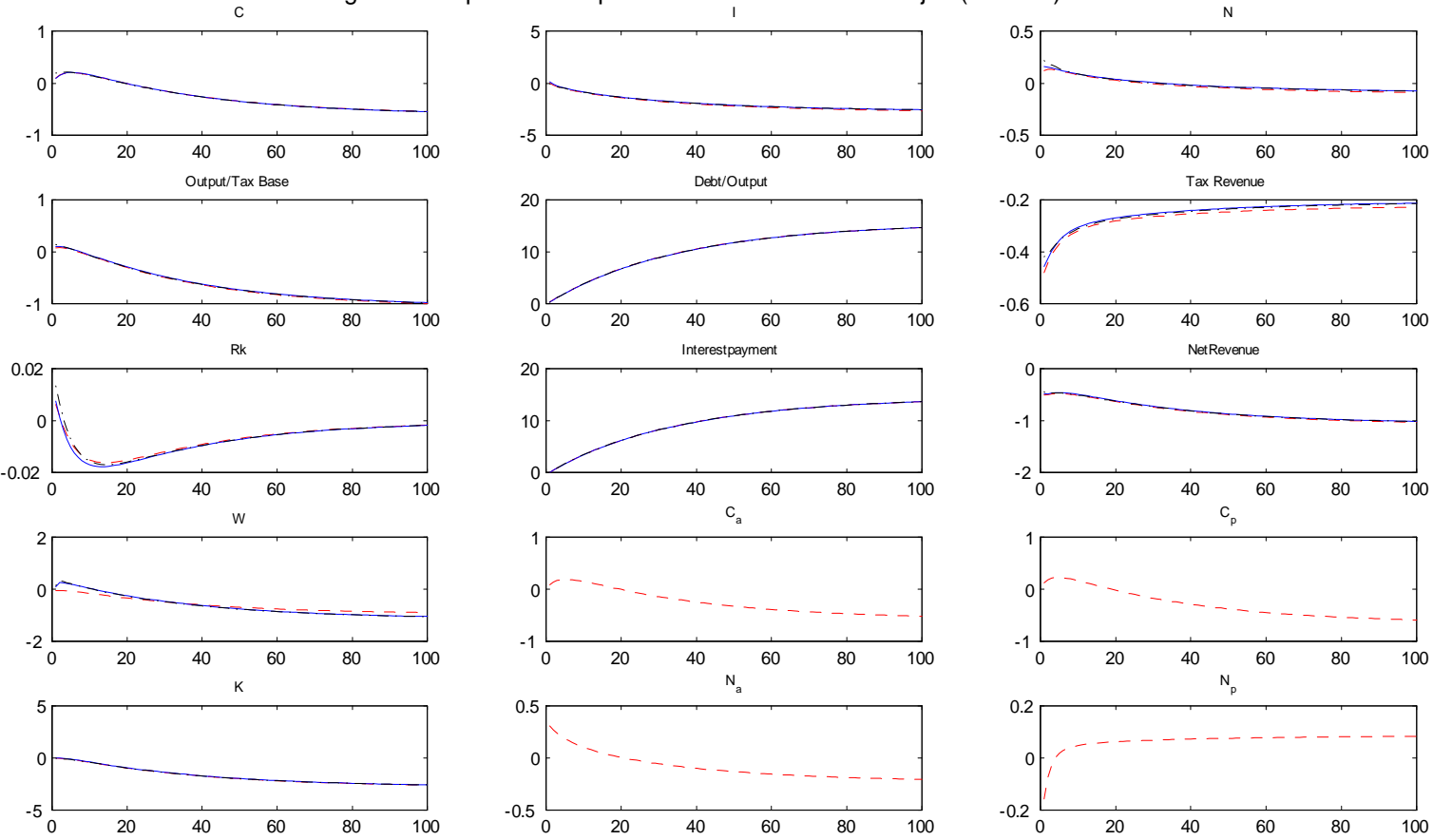

Figure 1:Model 1. Figure analyzes the impulse response of a permanent $1 \%$ decline in capital tax cut financed by Lump-sum transfers to both the saver and the spender. Dotted line - SS model; the solid line - MLY model; dotted-dashed - OLY model.

Figure 2:Response to Capital Tax Shock:Tranfers Adjust(Model 2)
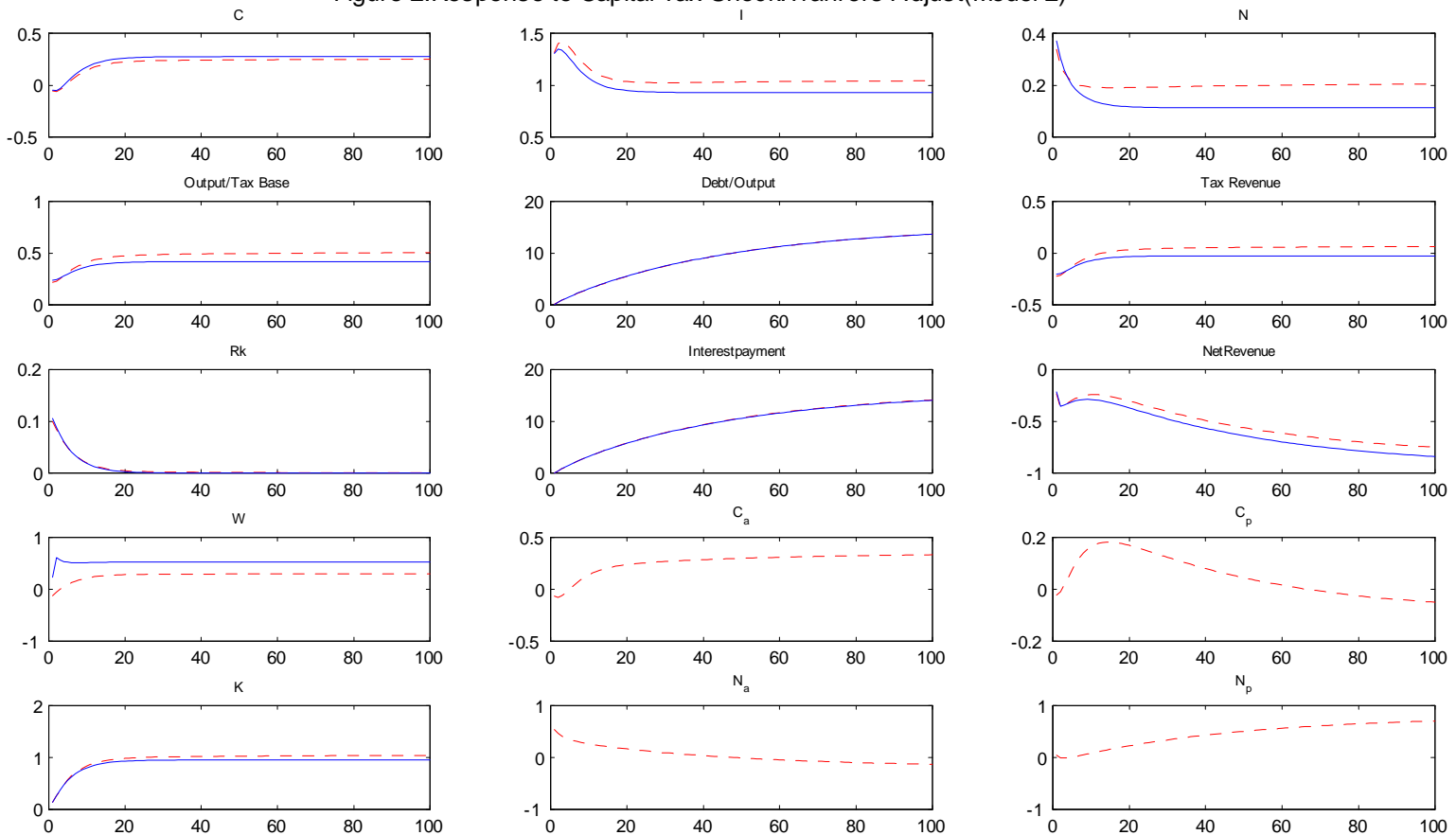

Figure 2:Model 2. Figure analyzes the impulse response of Capital tax-Transfer experiment. Dotted line - SS model; solid line - MLY model. 
Figure 3:Response to Capital Tax Shock:Tranfers Adjust(Model 4)
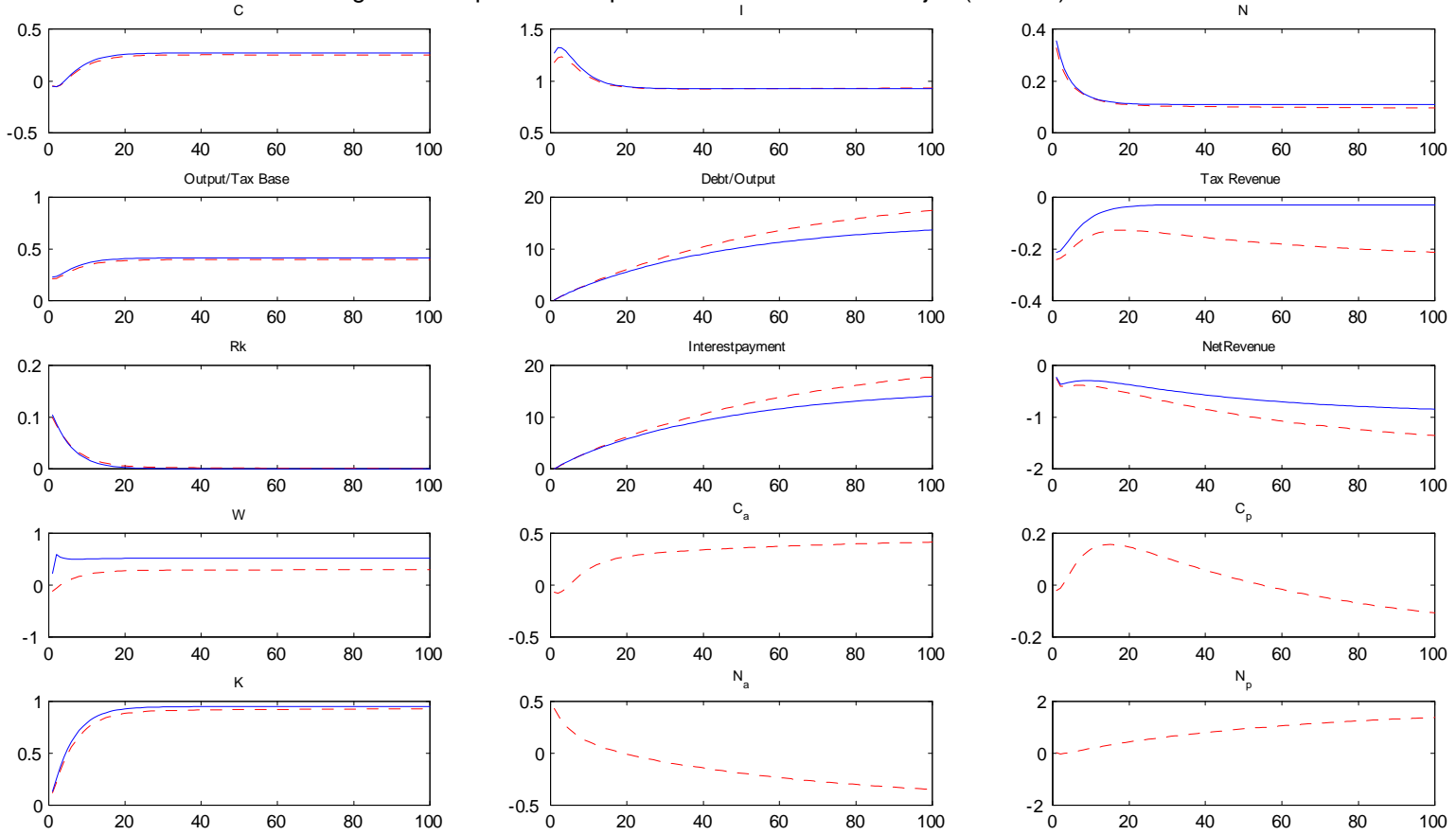

Figure 3: Model 4. Figure analyzes the impulse response of Capital tax-Transferexperiment. Dotted line - SS model; solid line - MLY model.

Figure 4:Response to Labor Tax Shock:Transfers Adjust(Model 1)
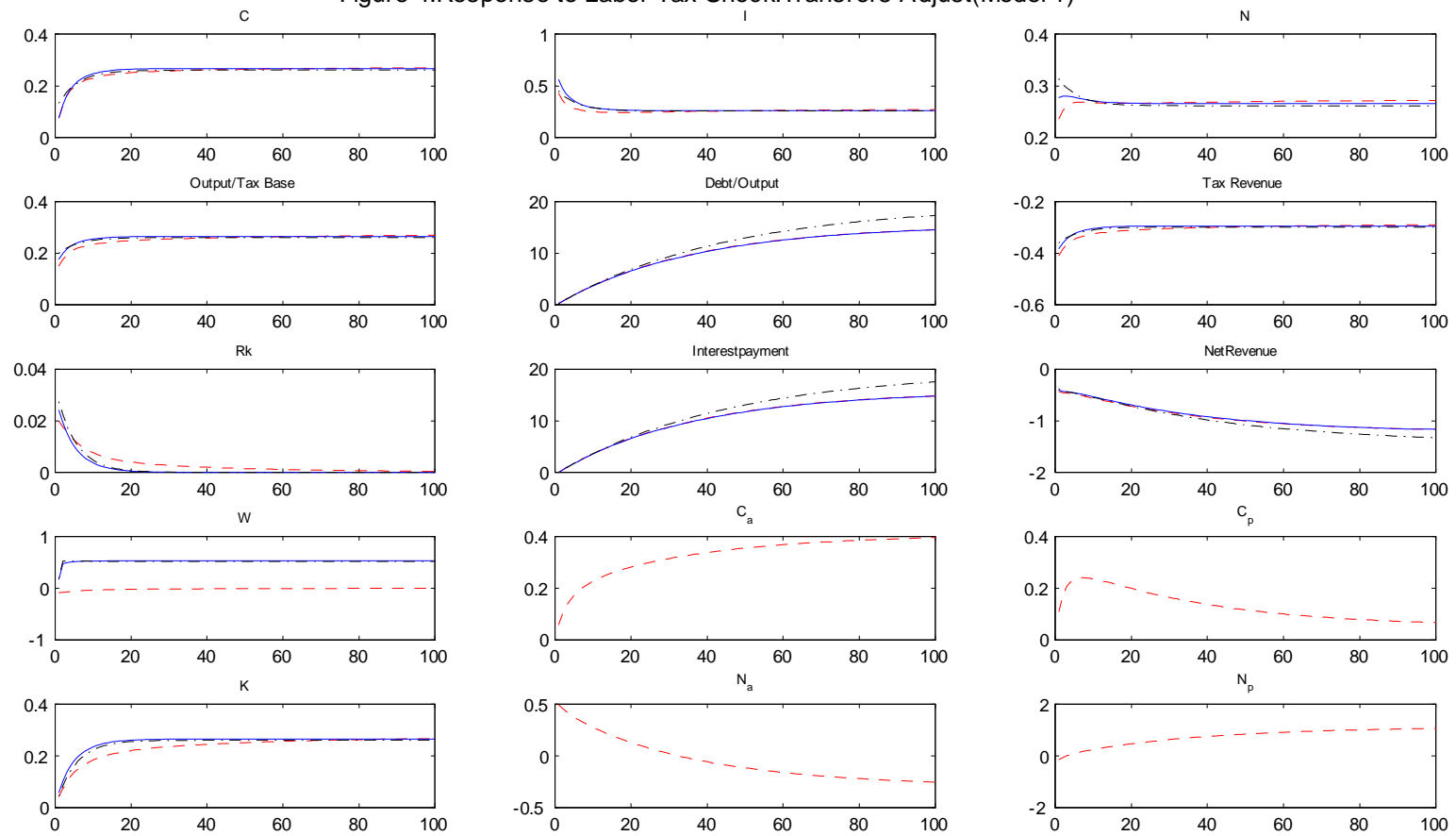

Figure 4: Model 1, the baseline SS model with no preference or tax heterogeneity. Figure analyzes the impulse response of a permanent $1 \%$ decline in labor tax cut financed by Lumpsum transfers to both the saver and the spender. Dotted line - SS model; the solid line - MLY model; dotted-dashed - OLY model. 
Figure 5:Response to labor Tax Shock:Tranfers Adjust(Model 2)
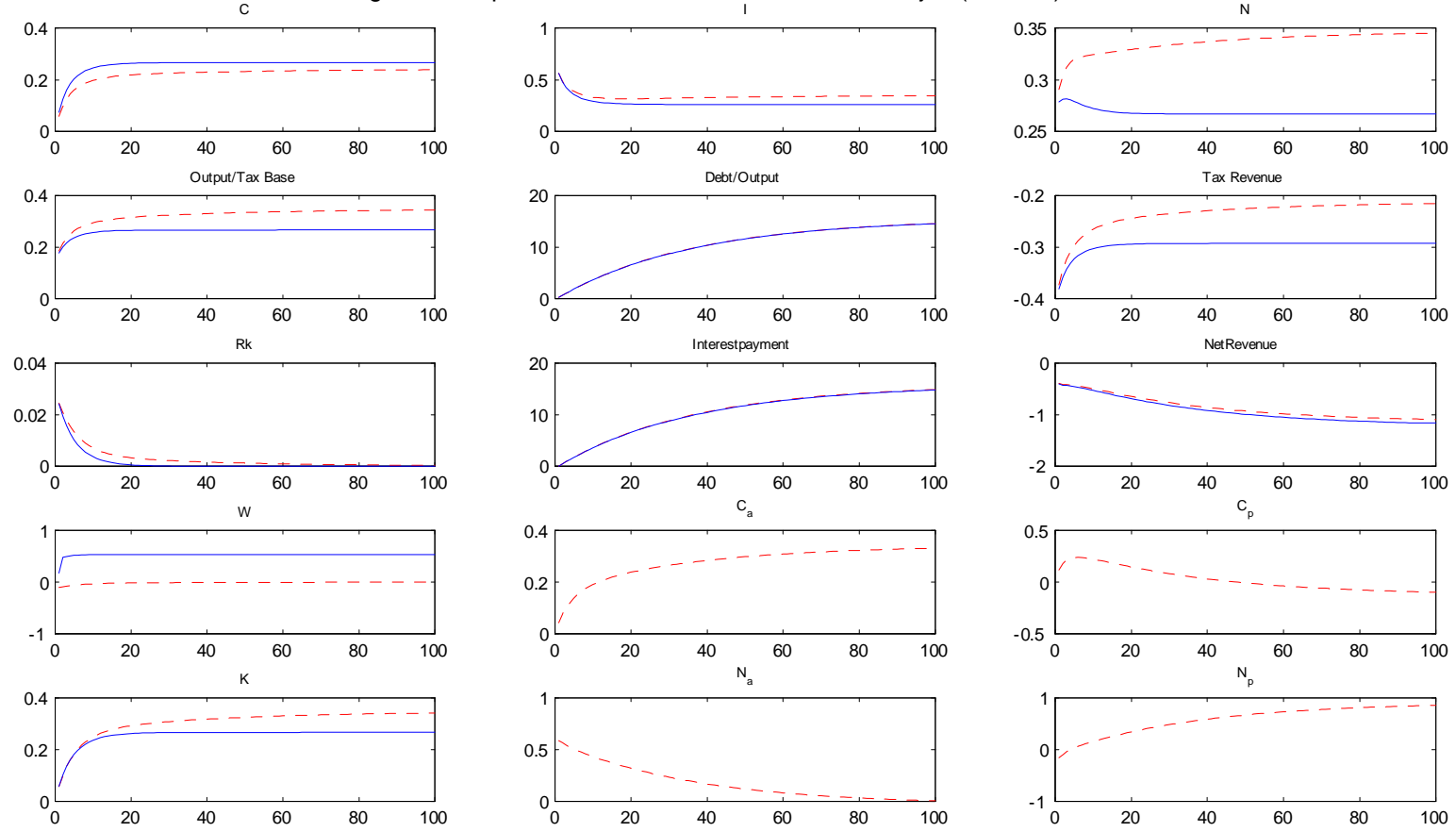

Figure 5: Model 2. Figure analyzes the impulse response of a Labor tax-Transfer experiment. Dotted line - SS model; solid line - MLY model.

Figure 6:Response to Labor Tax Shock:Tranfers Adjust(Model 4)
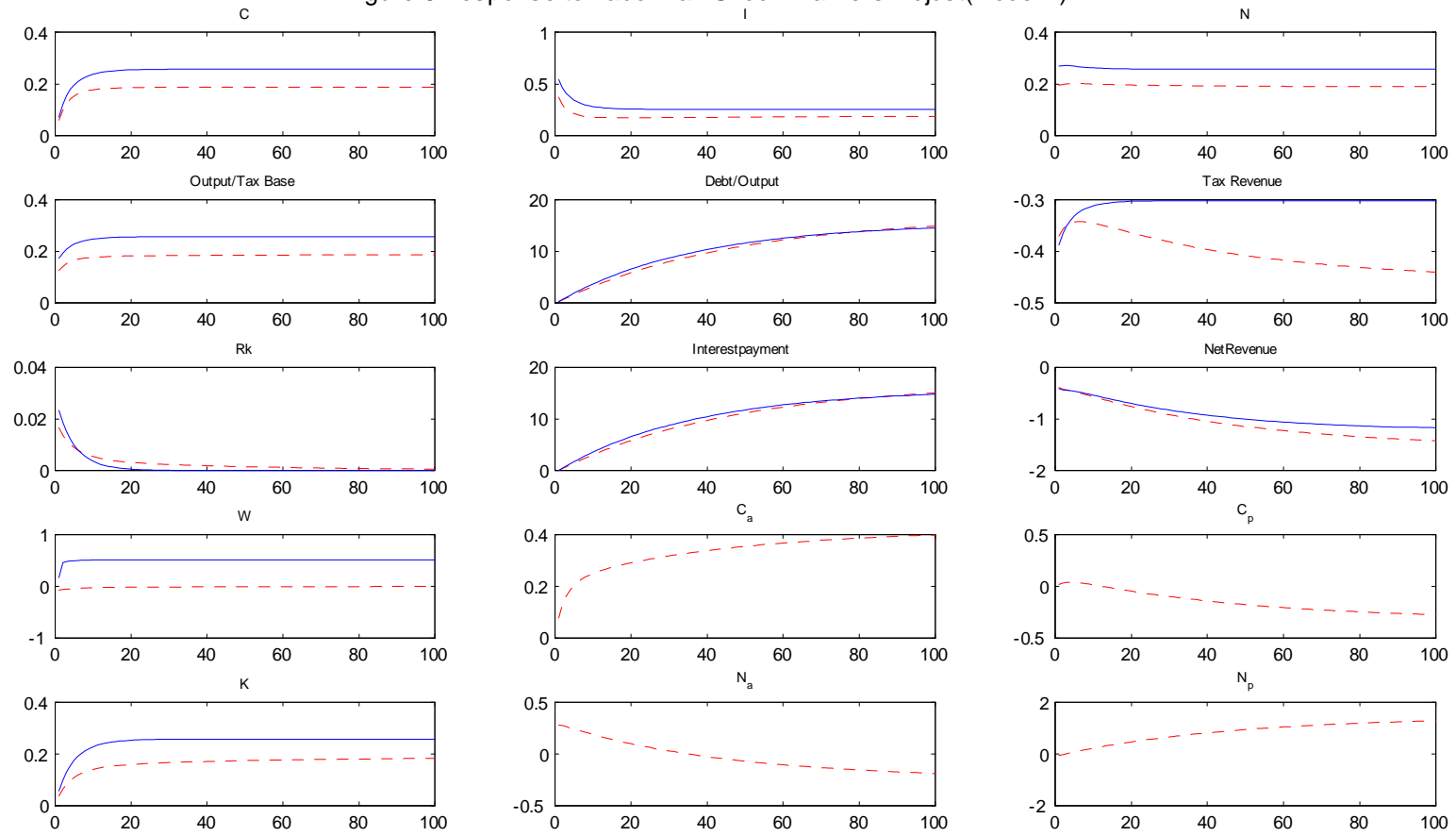

Figure 6:Model 4.Figure analyzes the impulse response of a Labor tax-Transfer experiment. Dotted line - SS model; solid line - MLY model. 
Figure 7:Response to Capital Tax Shock:Govt Spending adjust(Model 1)
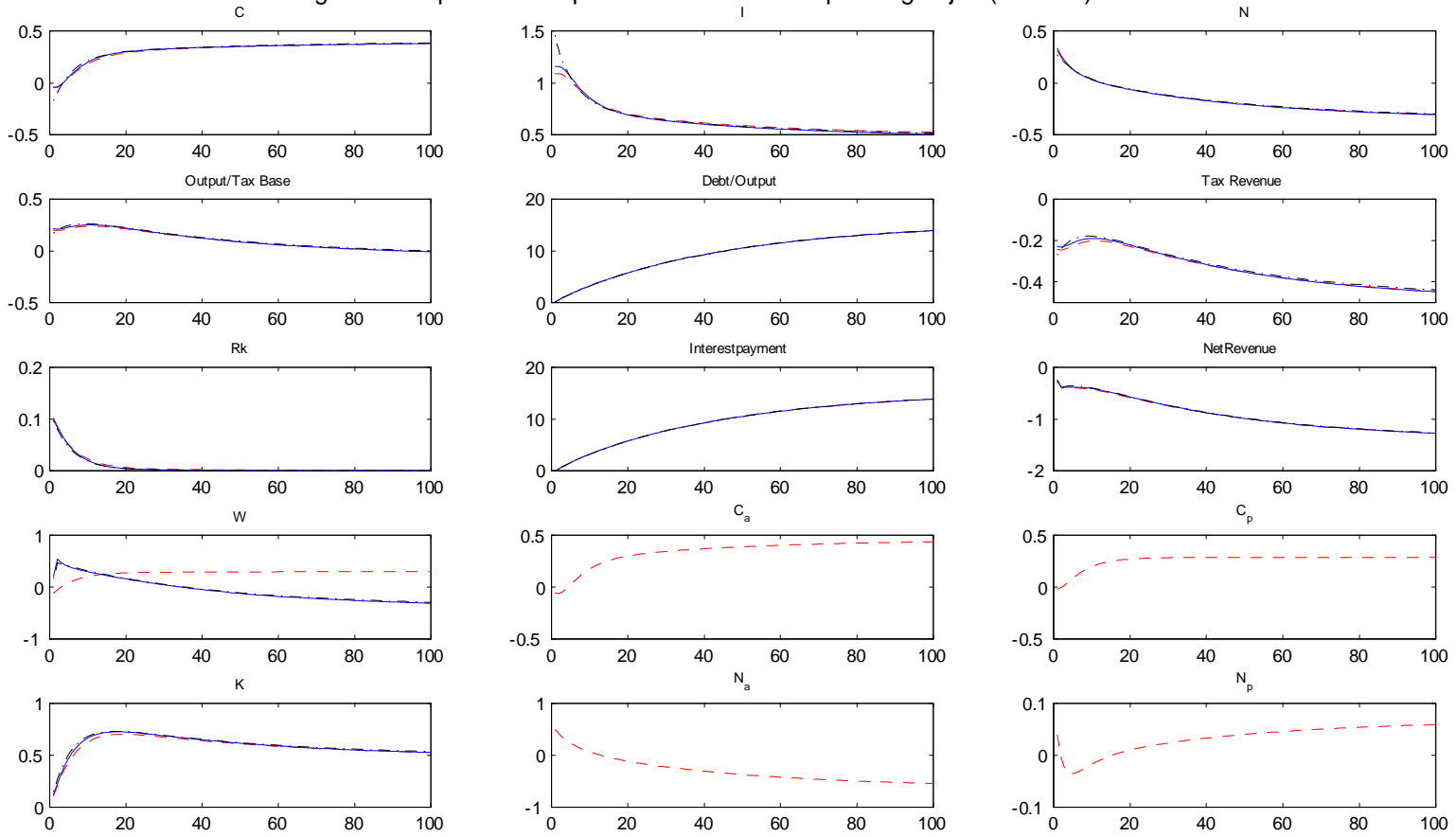

Figure 7:Model 1. Figure analyzes the impulse response of a permanent 1\% decline in Capital tax cut financed by Government spending . Dotted line - SS model; the solid line MLY model; dotted-dashed - OLY model.

Figure 8:Response to capital Tax Shock:Govt Spending adjust(Model 2)
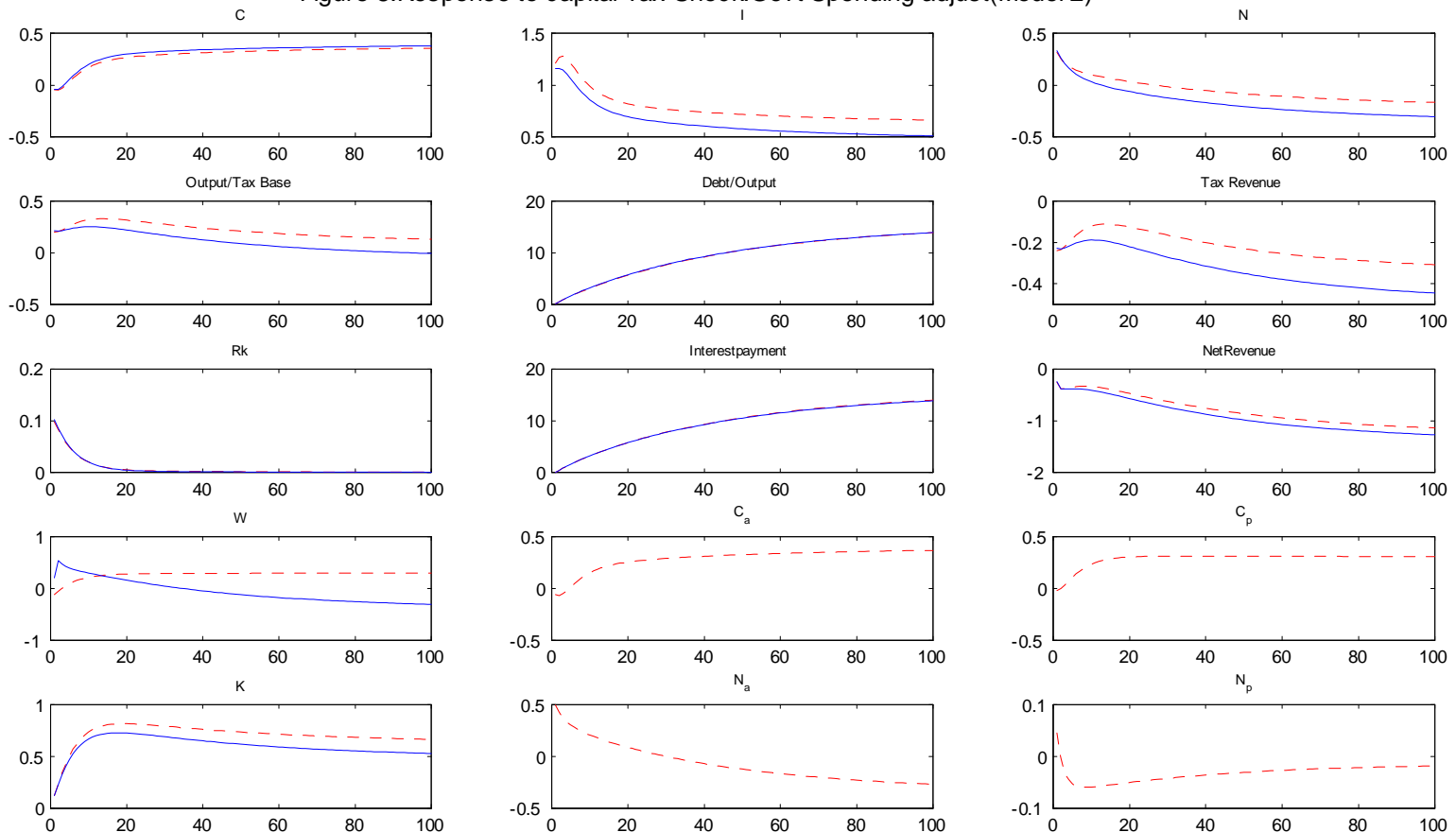

Figure 8:Model 2. Figure analyzes the impulse response of Capital tax-Spending experiment. Dotted line - SS model; solid line - MLY model. 
Figure 9:Response to capital Tax Shock:Govt spending adjust(Model 3)
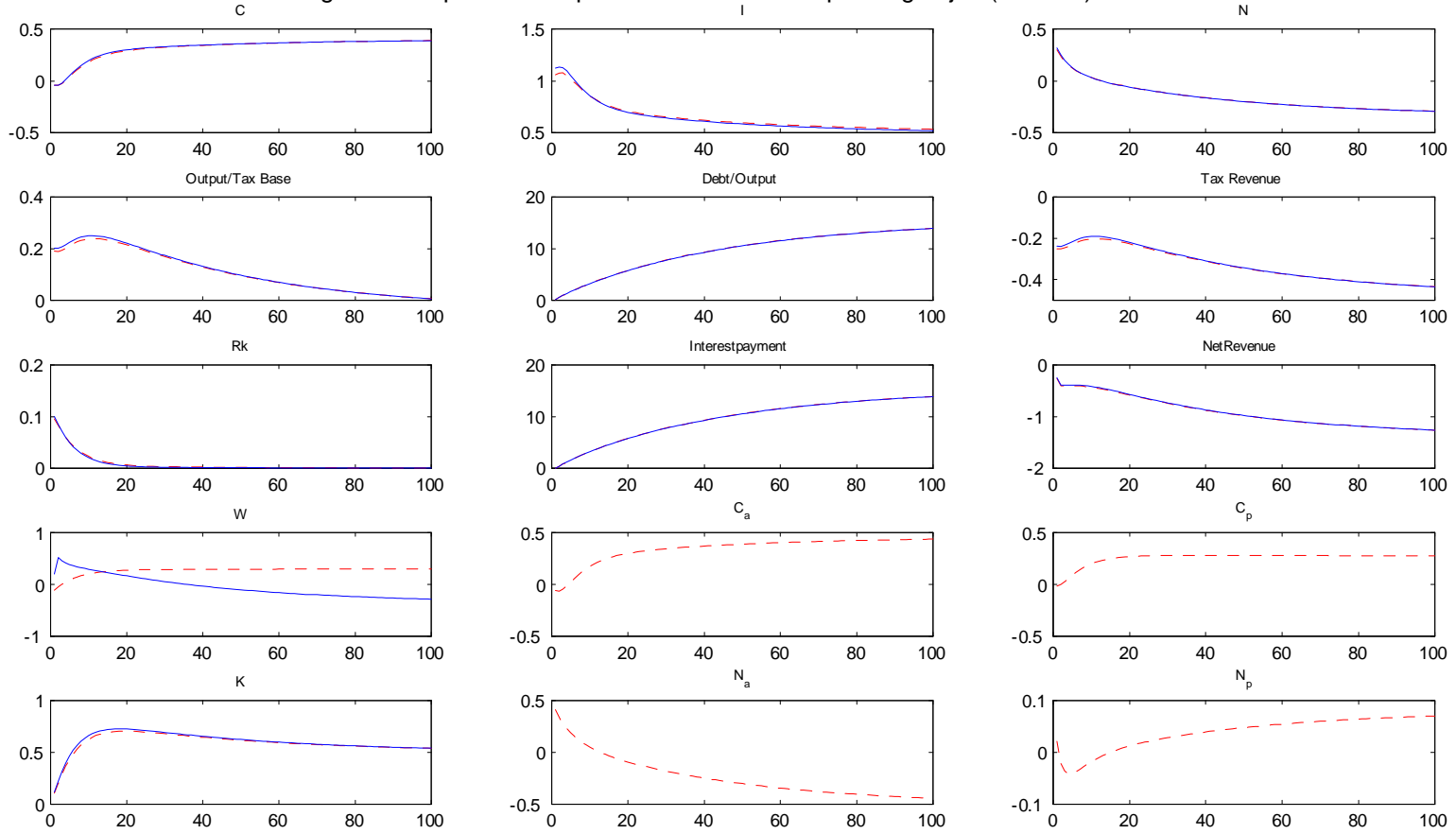

Figure 9:Model 3. Figure analyzes the impulse response of Capital tax-Spending experiment. Dotted line - SS model; solid line - MLY model.

Figure 10:Response to capital Tax Shock:Govt spending adjust(Model 4)
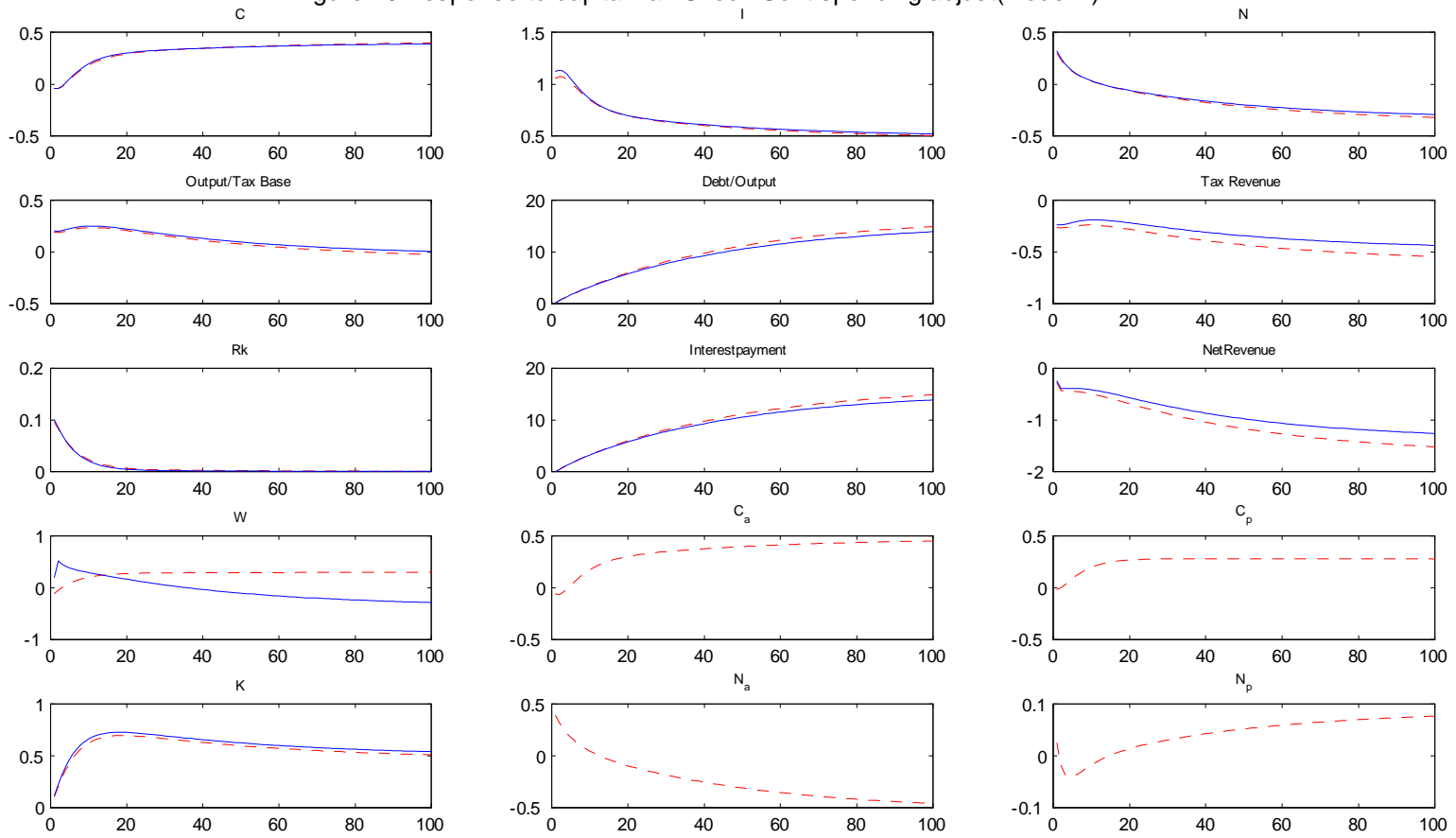

Figure 10: Model 4. Figure analyzes the impulse response of Capital tax-Spending experiment. Dotted line - SS model; solid line - MLY model. 
Figure 11:Response to Labor Tax Shock:Government spending adjust(Model 1)
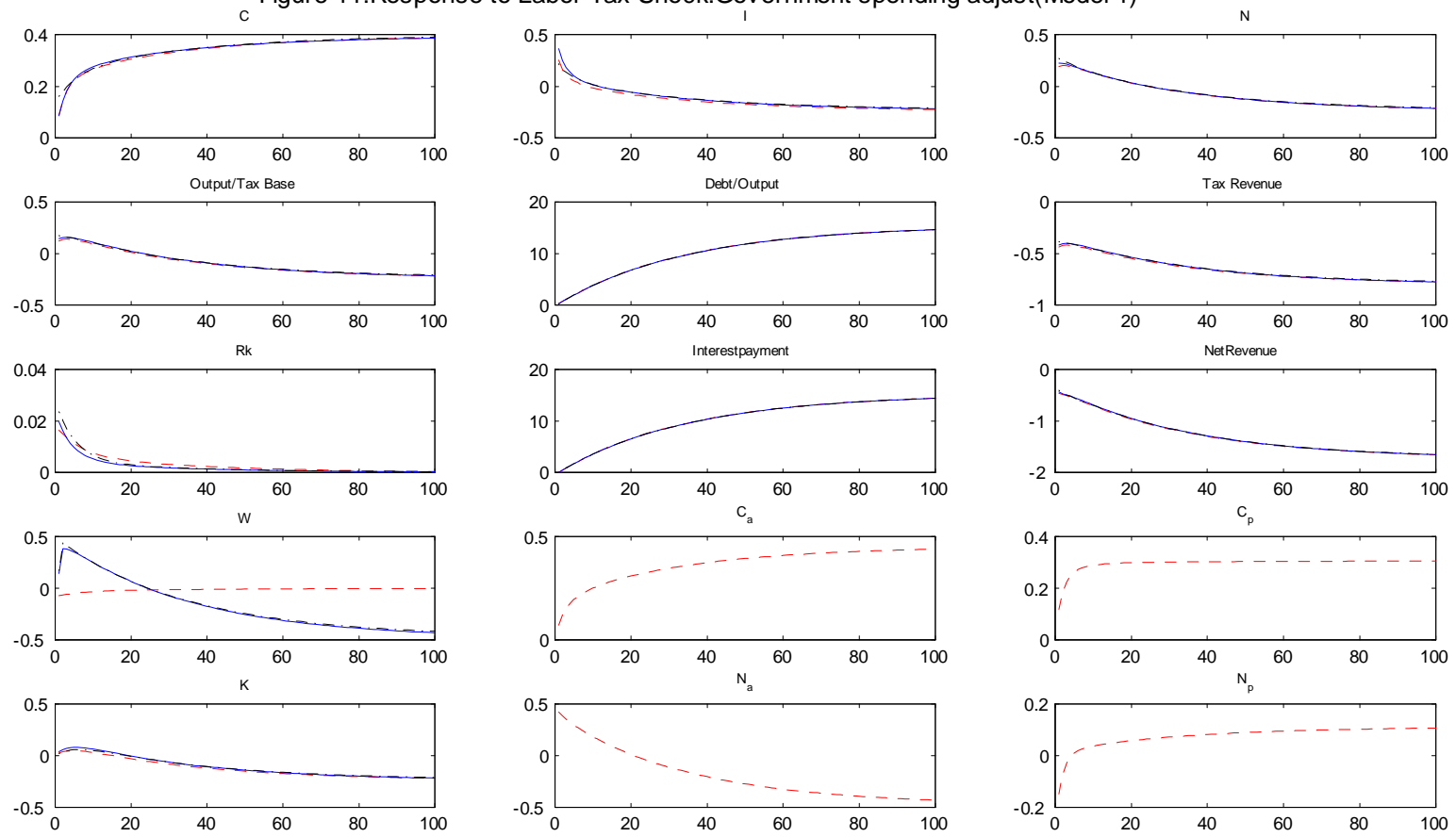

Figure 11:Model 1. Figure analyzes the impulse response of a permanent 1\% decline in Labor tax cut financed by Government spending. Dotted line - SS model; the solid line MLY model; dotted-dashed - OLY model.

Figure 12:Response to Labor Tax Shock:Govt Spending Adjust(Model 2)
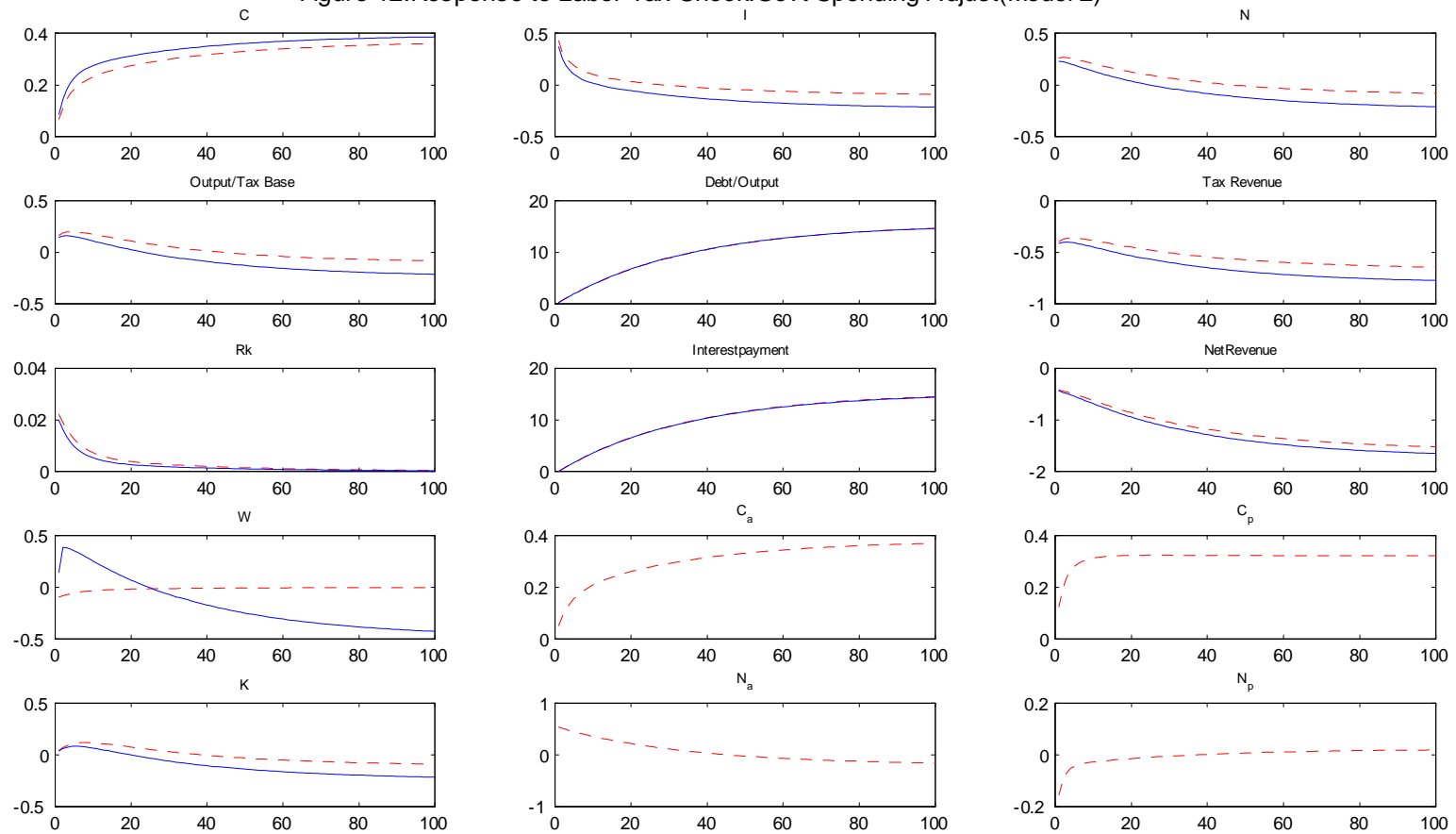

Figure 12: Model 2. Figure analyzes the impulse response of Labor tax-Spending experiment. Dotted line - SS model; solid line - MLY model. 
Figure 13:Response to Labour Tax Shock:Govt Spending Adjust(Model 4)
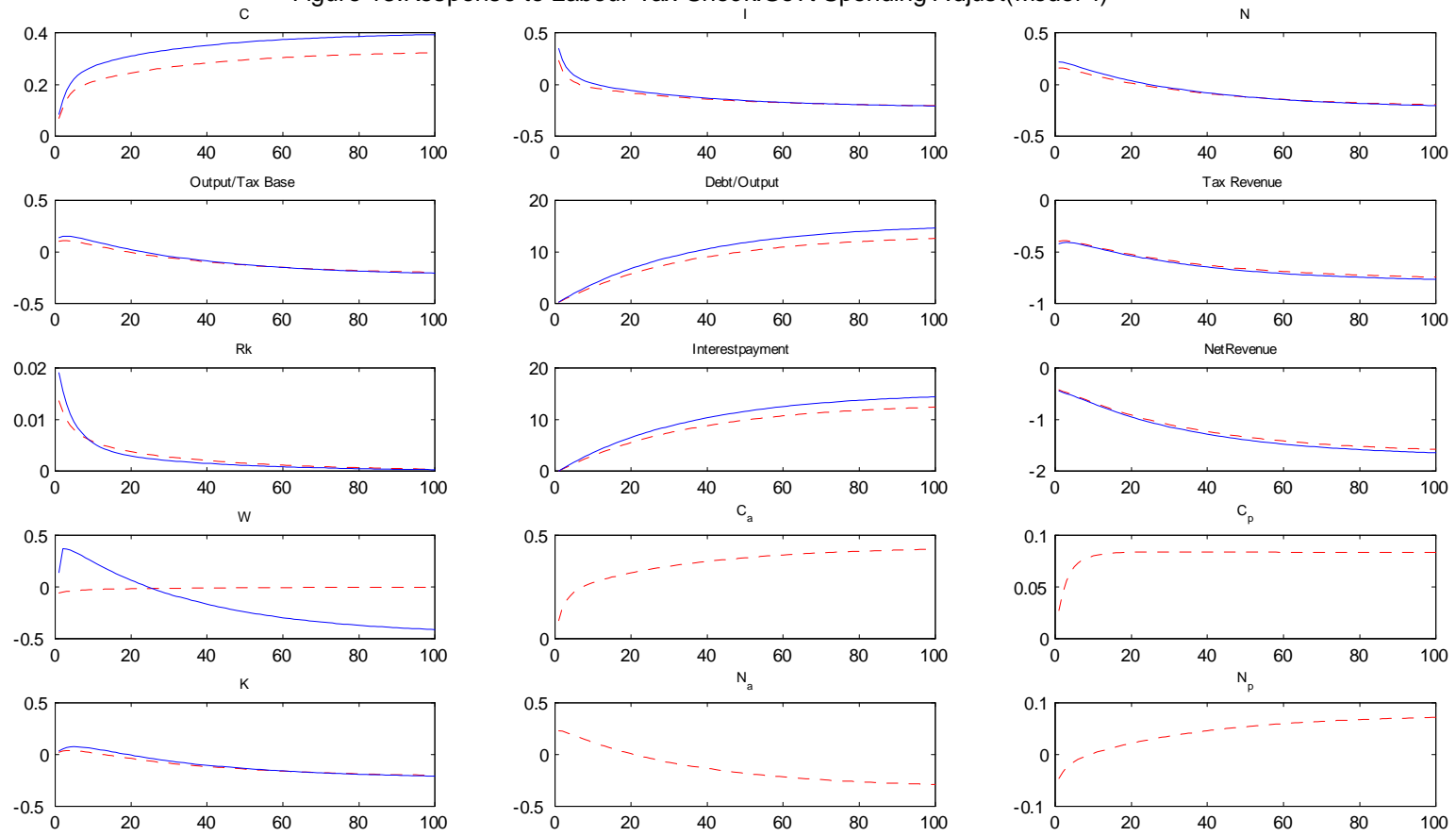

Figure 13:Model 4. Figure analyzes the impulse response of Labor tax-Spending experiment. Dotted line - SS model; solid line - MLY model.

Figure 14:Response to Capital Tax Shock:Labor Tax adjus(Model 1)
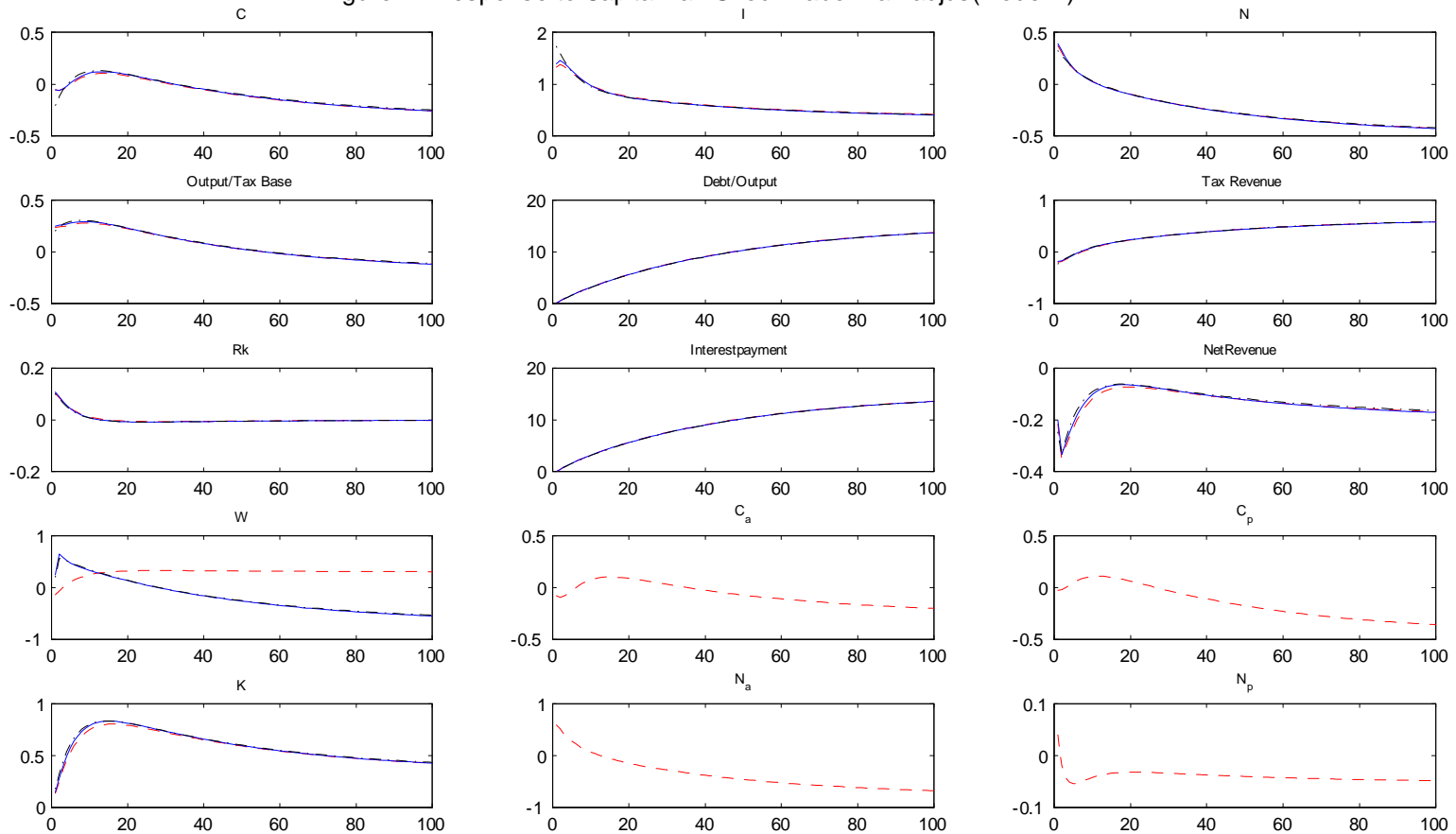

Figure 14:Model 1. Figure analyzes the impulse response of a permanent $1 \%$ decline in Capital tax cut financed by Labor tax. Dotted line - SS model; the solid line - MLY model; dotted-dashed - OLY model. 
Figure 15:Response to capital Tax Shock:Labor Tax Adjusts(Model 4)
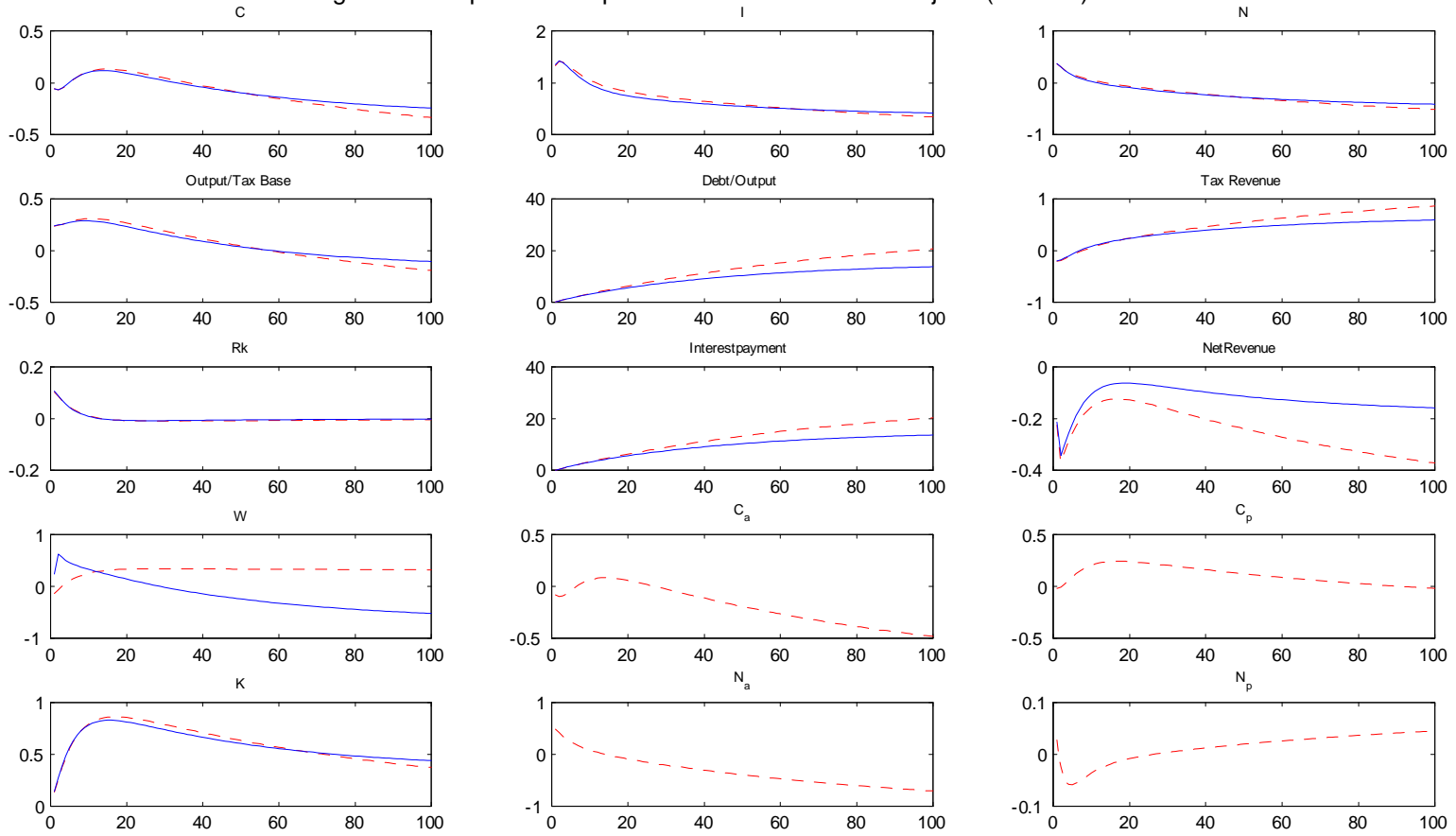

Figure 15:Model 4. Figure analyzes the impulse response of Capital tax-Labor tax experiment. Dotted line - SS model; solid line - MLY model.

Figure 16:Response to Labor Tax Shock:Capital Tax adjust(Model 1)
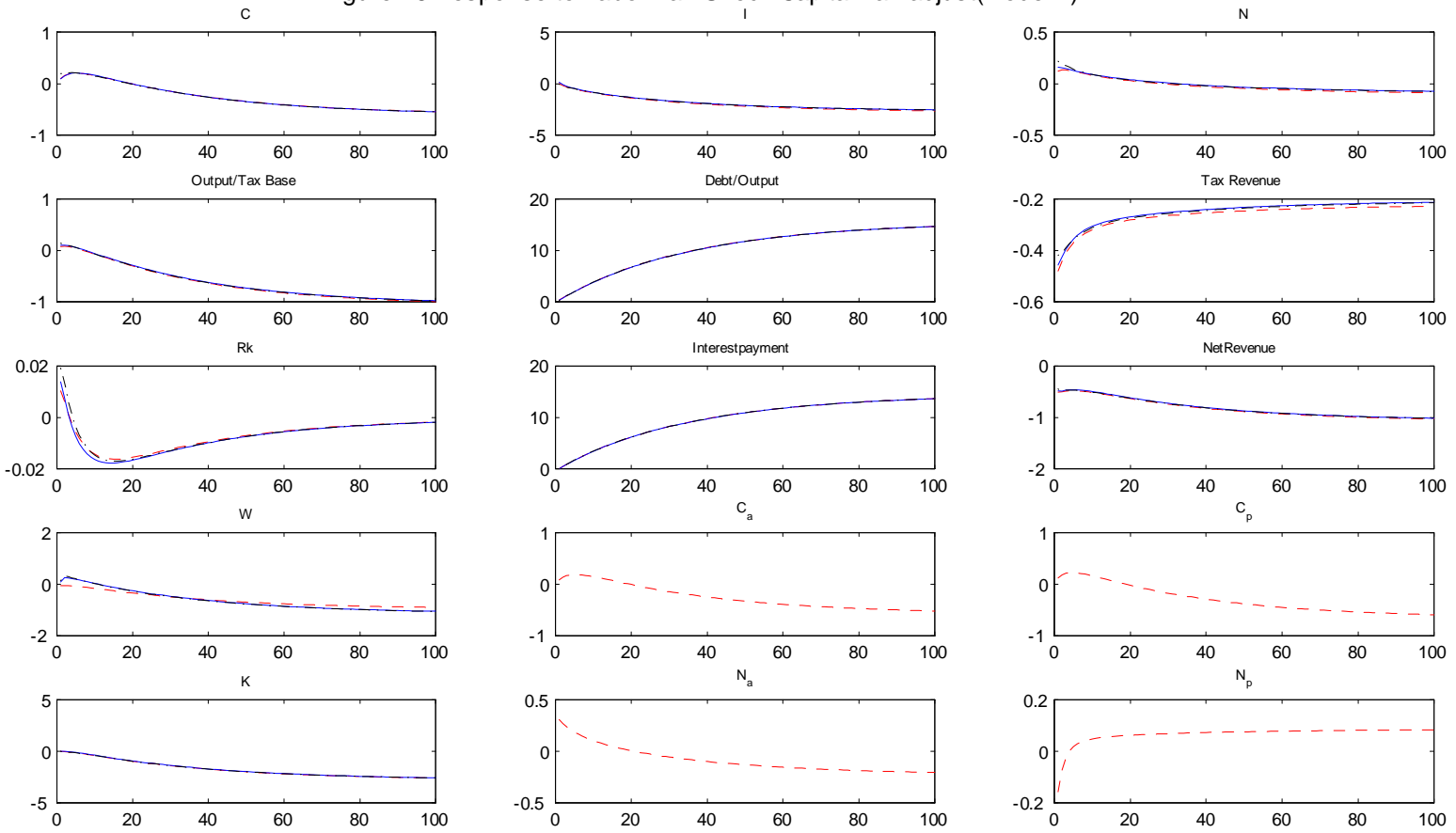

Figure 16:Model 1. Figure analyzes the impulse response of a permanent 1\% decline in Labor tax cut financed by Capital tax. Dotted line - SS model; the solid line - MLY model; dotted-dashed - OLY model. 
Figure 17:Response to labor Tax Shock:Capital tax adjust(Model 2)
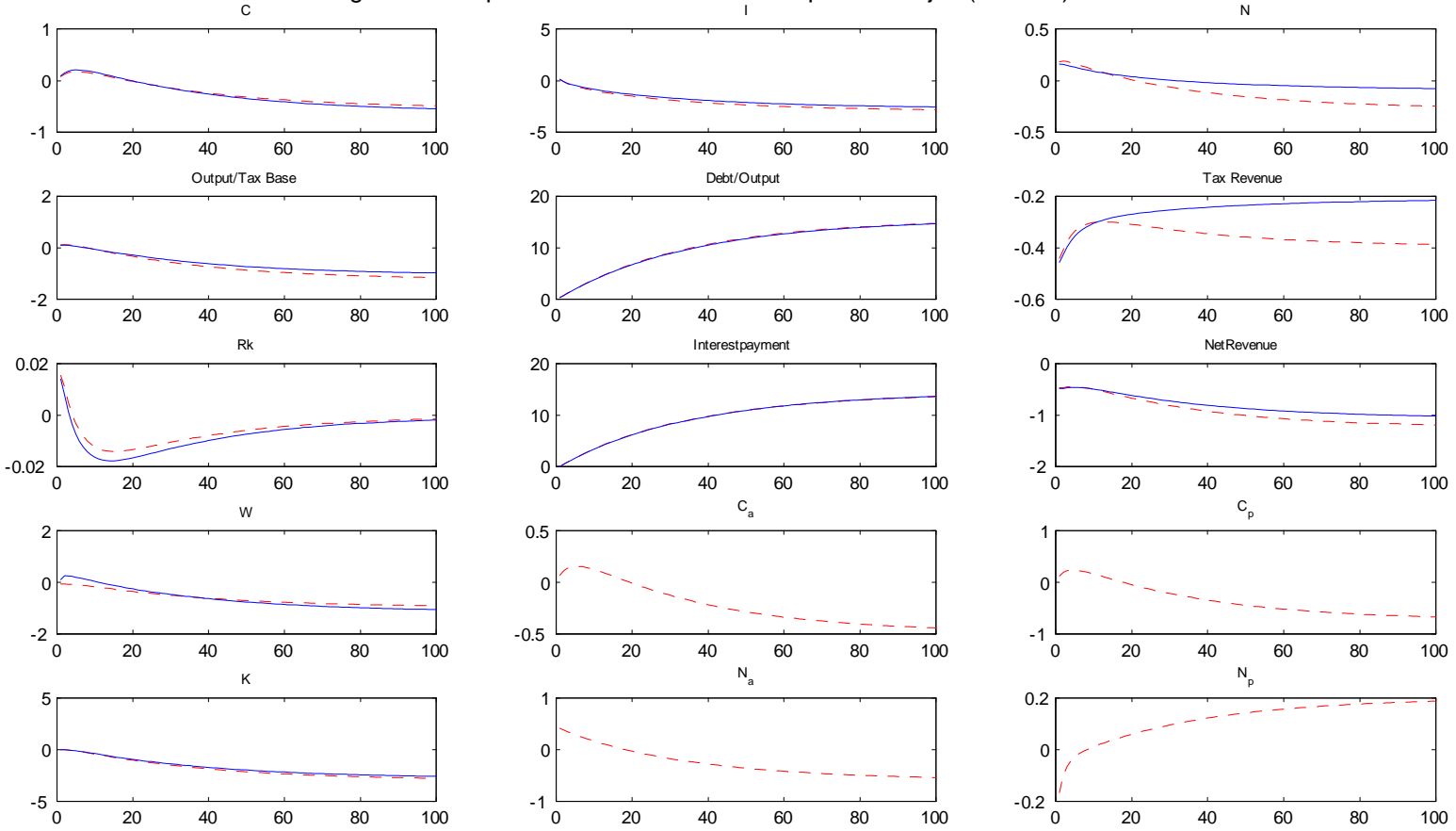

Figure 17:Model 2. Figure analyzes the impulse response of labor tax-capital tax experiment. Dotted line - SS model; solid line - MLY model.

Figure 18:Response to Labour Tax Shock:capital tax Adjust(Model 4)
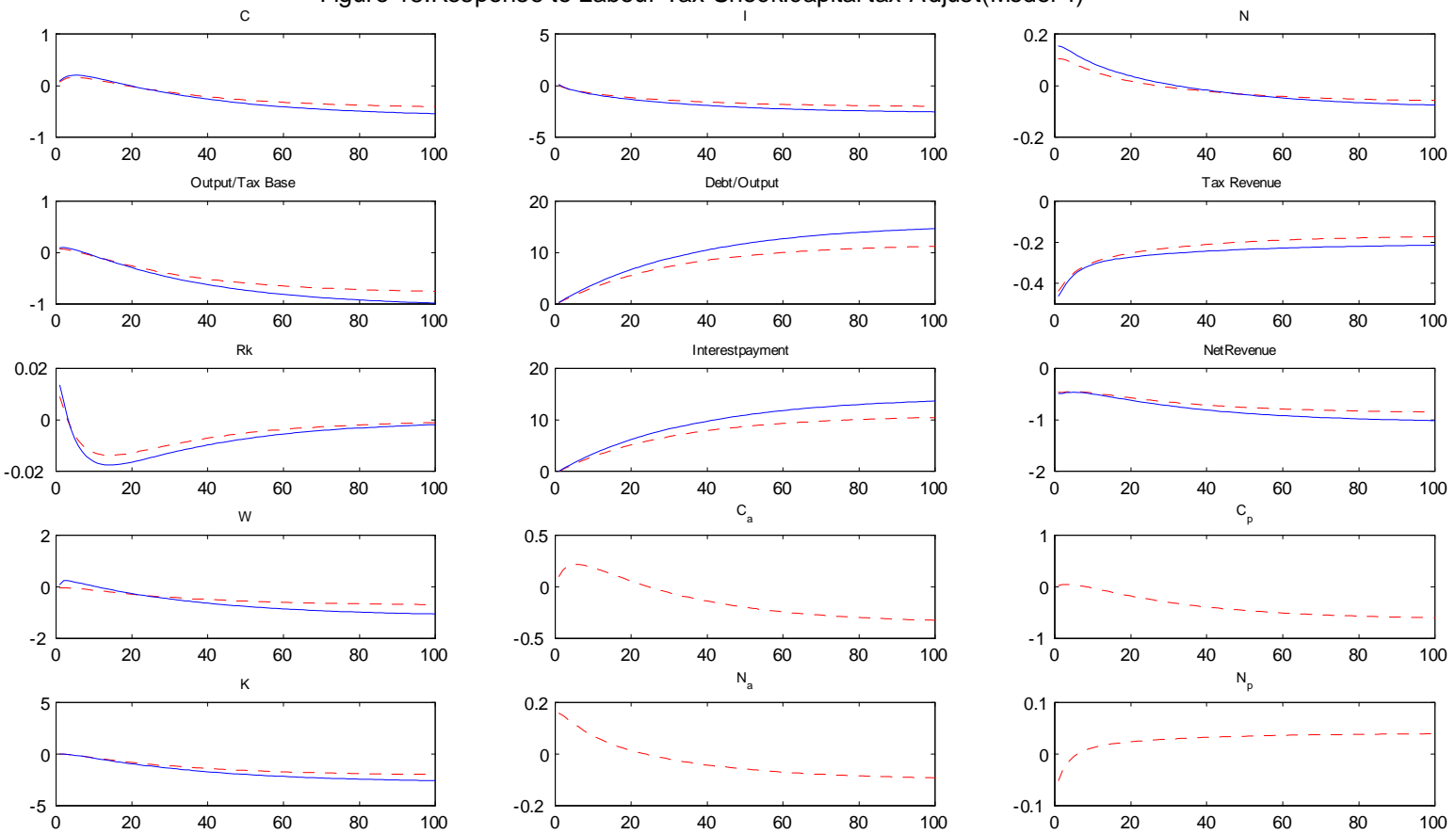

Figure 18:Model 4.Figure analyzes the impulse response of labor tax-capital tax experiment. Dotted line - SS model; solid line - MLY model. 

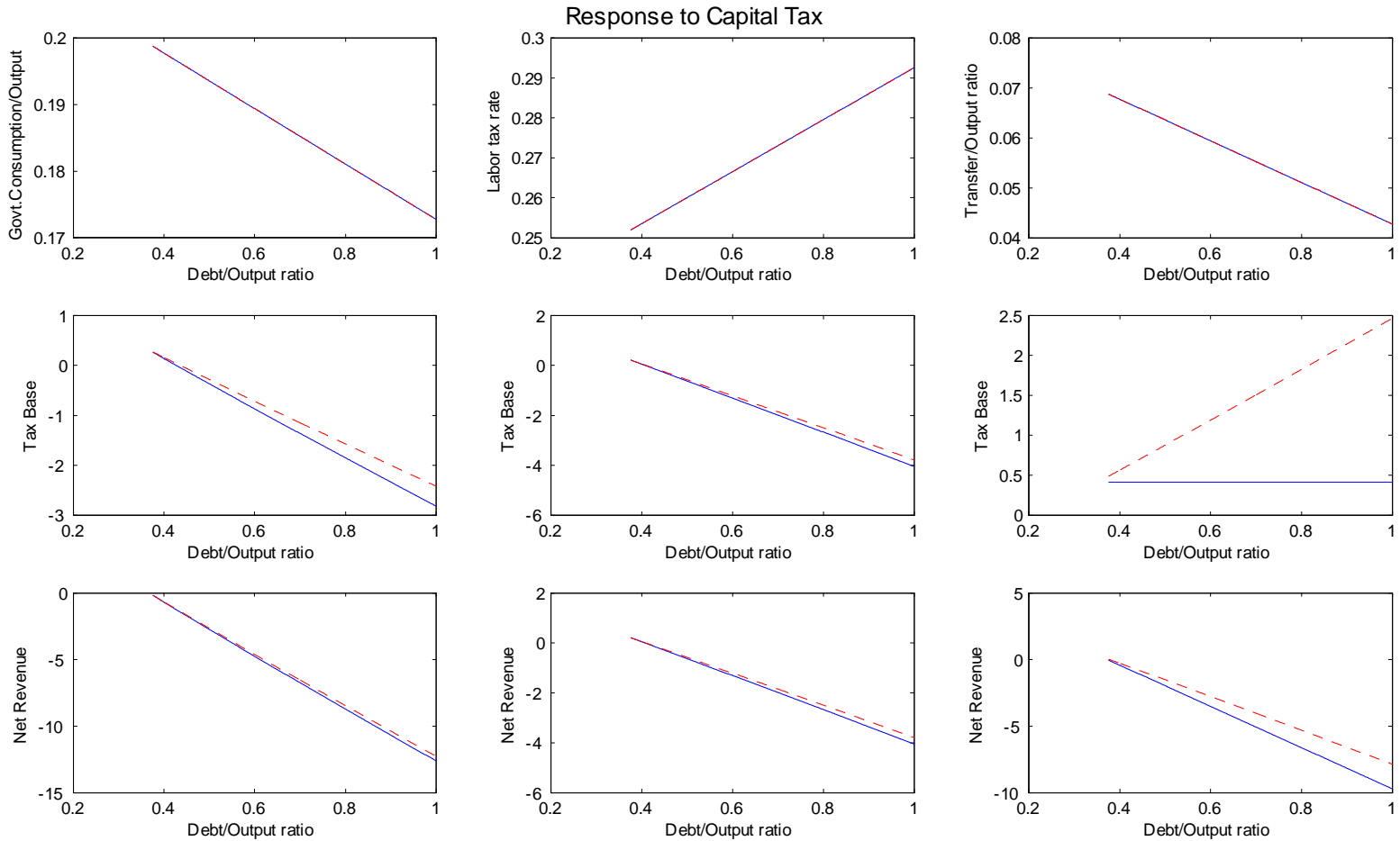

Figure 19:Steady state Analysis.Figure plots the steady state response of a permanent 1\% Capital tax rate cut. Solid line - MLY model; Dashed line-SS model. First column-govt consumption adjusts; second column-labor tax adjusts; third column-transfers adjust. Fiscal instruments are in levels.; tax base and net revenue are percent changes relative to pre-tax cut steady states.
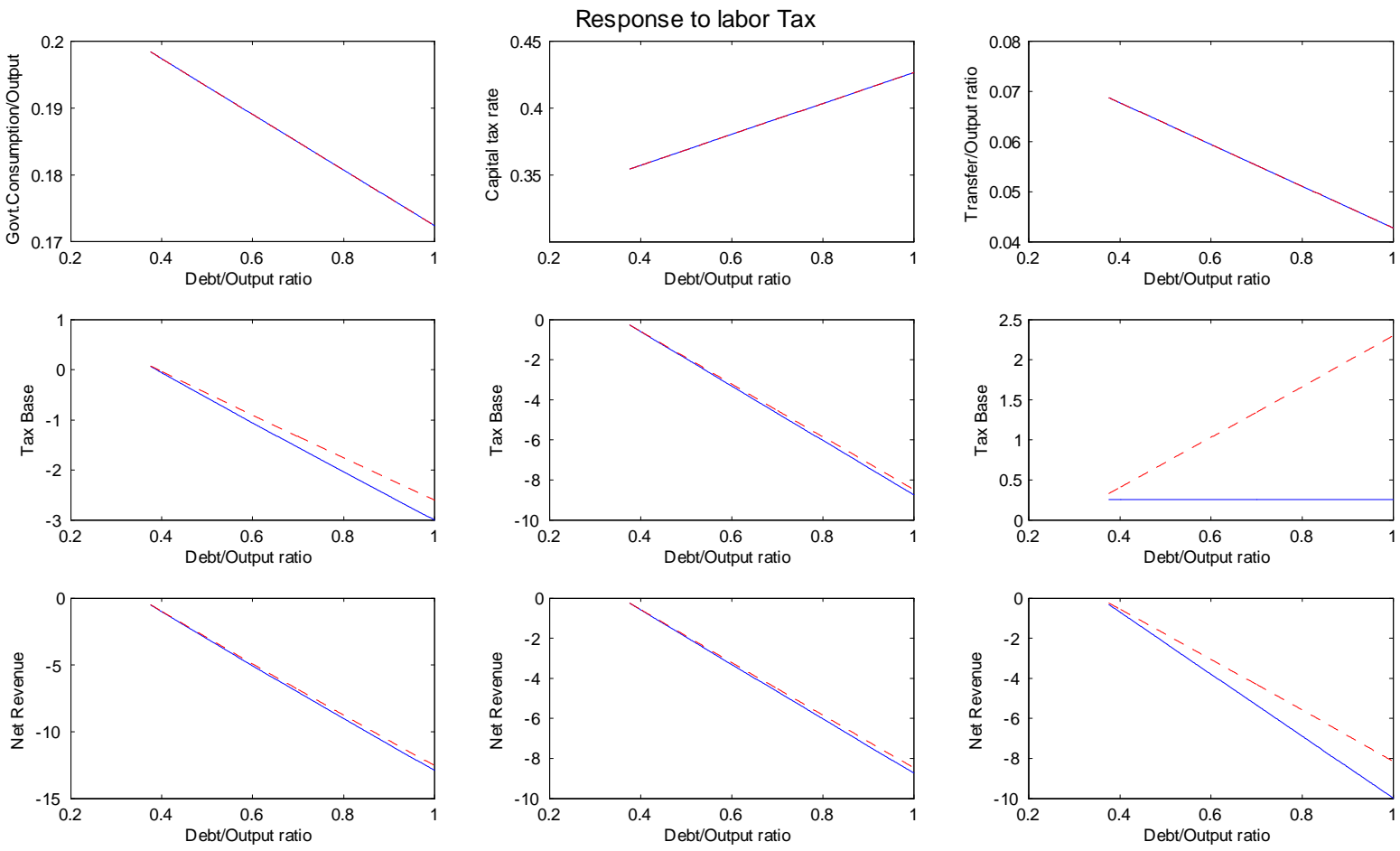

Figure20: Figure plots the steady stater esponse of a permanent $1 \%$ labor tax rate cut. 